\title{
Records of scuttle flies (Diptera, Phoridae) visiting flowers of Cryptogorynae crispatula (Araceae), including new species, in China
}

\author{
R. Henry L. DISNEY \\ Department of Zoology, University of Cambridge, Cambridge CB2 3EJ, England; e-mail: rhld2@hermes.cam.ac.uk
}

\begin{abstract}
The collection of the scuttle flies (Diptera, Phoridae) visiting flowers of Cryptogorynae crispatula (Araceae) caught in Yunnan, China were studied. They were identified to 24 species of which only five were known, seven species are hereby described as new to science and next 13 species cannot be named until linked to their opposite sexes. The following are described. Conicera species female YG, cannot be named until linked to its male. Dohrniphora guangchuni n. sp., Megaselia duolobata n. sp., M. excrispatula n. sp., M. interstinctus n. sp., M. leptotibiarum n. sp., M. menglaensis n. sp., M. shooklinglowae n. sp., Megaselia species Y1 female that cannot be named until linked to its male. The recognition of $M$. chippensis (Brues, 1911), described from a single female, is augmented. Males of 6 species (Y1-Y6) of Puliciphora Dahl, cannot be named until linked to their females and 5 species of Woodiphora Schmitz.
\end{abstract}

Key words: Phoridae, China, Yunnan, new species.

\section{INTRODUCTION}

Low Shook Ling (Paleoecology Group, Xishuangbanna Tropical Botanical Garden, Chinese Academy of Sciences, Menglun, Mengla) caught the insects visiting flowers of Cryptogorynae crispatula (Araceae) in Yunnan, China and sent me the scuttle flies (Diptera, Phoridae) for identification. These represent 24 species of which 5 were known species, 6 are new species that are described below and 13 species that cannot be named until linked to their opposite sexes.

\section{METHODS}

The specimens were preserved in $70 \%$ ethanol and mounted on slides in Berlese Fluid (Disney, 2001). The specimens are deposited in the University of Cambridge Museum of Zoology (UCMZ).

\section{RESULTS}

\section{Conicera Meigen}

Almost forty species are known in the genus Conicera Meigen. Recognition of the species is currently based on the males. Currently females can only be named when linked to their males. Males of the Oriental species are keyed by Disney (1990c), supplemented by Disney (2009), Disney, Lizon å l'Allemand et al. (2009), Zang \& Liu, 2009); and the Chinese species are keyed by Liu (2000), who adds six new species, which are also covered by Liu (2001). Bänziger \& Disney (2006) add a further Oriental species. The species described below differs from all females described so far. However, a female sent by Guangchun Liu many years ago is the same species. 


\section{Conicera species YG, female}

(Figs 1-5)

Description. Female. Head as Fig. 1. Frons as Fig. 2. Side of thorax as Fig. 3. Abdominal tergites $4-6$ as Fig. 4. Hind tibia as Fig. 5. Wing $1.76 \mathrm{~mm}$ long. Costal index 0.52. Costal cilia $0.04 \mathrm{~mm}$. The single axillary bristle $0.17 \mathrm{~mm}$ long.

Material. Female, China, Yunnan, ManNaXing Village $(10 \mathrm{~km}$ distance from Xishuangbanna Tropical Botanical Garden), Mengla, Yunnan, China, GPS: 21.875190 N, 102.277401 E, Elevation: 600 m a.s.1, 30 Mar 2019, at male flower of Cryptogorynae crispatula, leg. Low Shook Ling (UCMZ, 28-65). Female, China, Guangdong, Dinghu, 24 Mar 1992, G. Liu (15, UCMZ, 5-126).

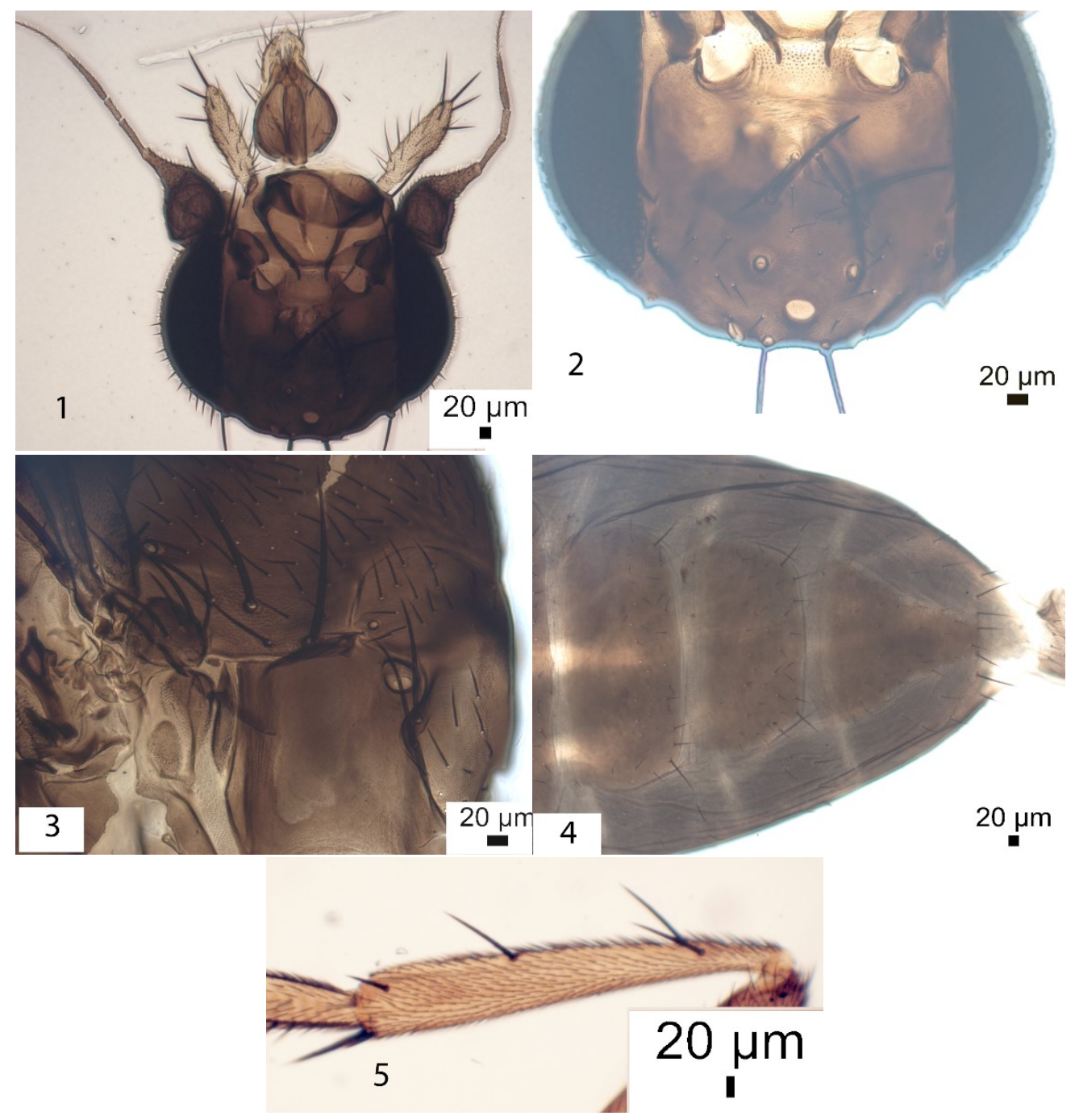

Figs 1-5. Conicera sp. YG female; 1 - head; 2 - frons; 3 - side of thorax; 4 - abdominal tergites 4-6; 5 - hind tibia. 
Dohrniphora Dall

\section{Dohrniphora guangchuni n. sp.}

(Figs 6-21)

Diagnosis. For the Oriental Region species of Dohrniphora Dall were keyed by Disney (1990b), Liu (2015) provided the most recent key to the species from China. His Fig. 56 depicts a male's hind coxal lobe of the species he attributed to D. leei Disney (2005b), a species previously known from South Korea. Liu's Fig. 56, however, differs from the lobes of $D$. leei (Figs 22-23) and differs from those of the species described below (Figs 14 \& 15). In addition the microsculpture of the posterior face of the hind femur has a distinct patch (Fig. 13) that is not present in D. leei. It was concluded that Liu's species is a new species, which he is describing elsewhere.
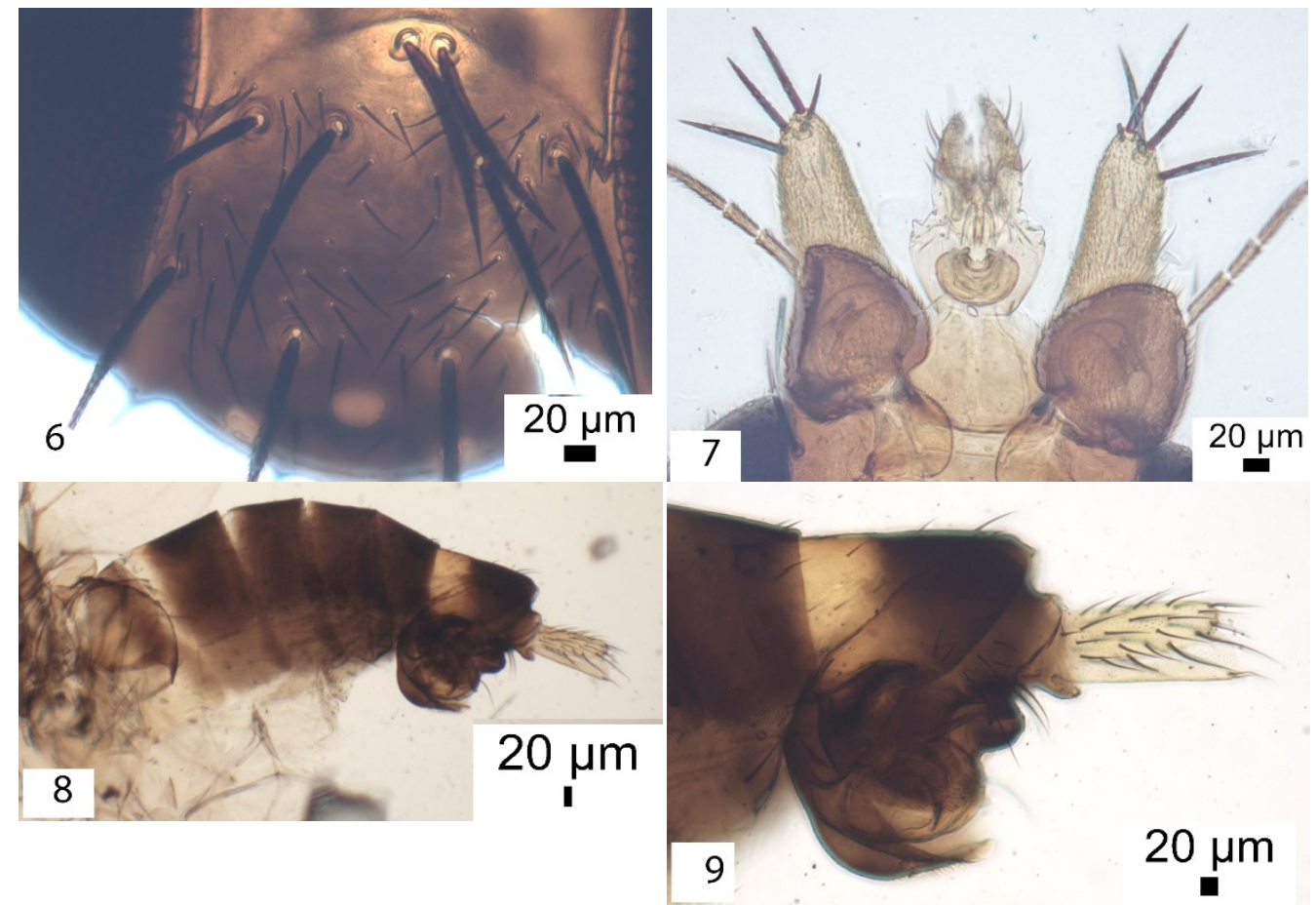

Figs 6-9. Dohrniphora guangchuni n. sp. male. 6 - frons; 7 - postpedicels, palps and proboscis; 8 - left face of abdomen; 9 - left face of hypopygium.

Description. Male. Frons as Fig. 6. Postpedicels, palps and proboscis as Fig. 7. Scutellum with an anterior pair of small hairs and a posterior pair of long bristles. Left face of abdomen as Fig. 8 and left face of hypopygium as Fig. 9. Front leg as Fig. 10. Mid tibia as Fig. 11, with posterodorsal hair palisade varying in length up to about 0.6 times its length. Posterior face of hind femur as Fig. 12, with a distinct microsculpture patch as Fig. 13. Hind coxal lobes as Figs $14 \& 15$. Hind tibia as Fig. 16. Wing (Fig. 17) 1.56-2.04 mm long. Costal index 0.48-0.53. Costal ratios $8.8-11.9: 2.5-3.3: 1$. Costal cilia $0.03-0.04 \mathrm{~mm}$ long. Vein 3 hair $0.04 \mathrm{~mm}$ long. The single axillary bristle $0.13-0.15 \mathrm{~mm}$ long. Haltere knob very pale. 


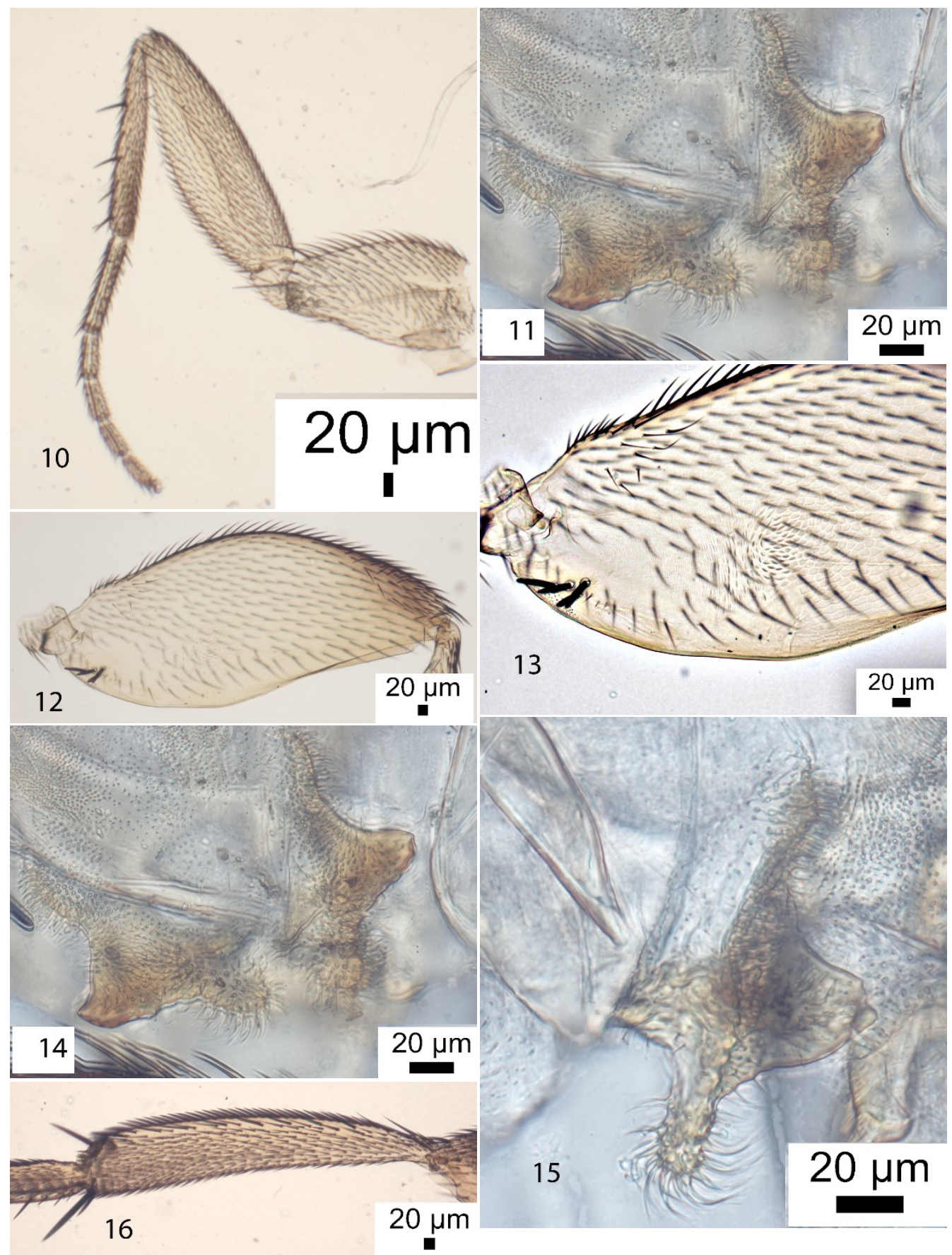

Figs 10-16. Dohrniphora guangchuni n. sp. male; 6 - frons; 7 - postpedicels, palps and proboscis; 8 - left face of abdomen; 9 - left face of hypopygium; 10 - front leg; 11 - mid femur to basitarsus; 12 - posterior face of hind femur, with a distinct microsculpture patch as Fig. 13; 14-15 - hind coxal lobes; 16 - hind tibia. 


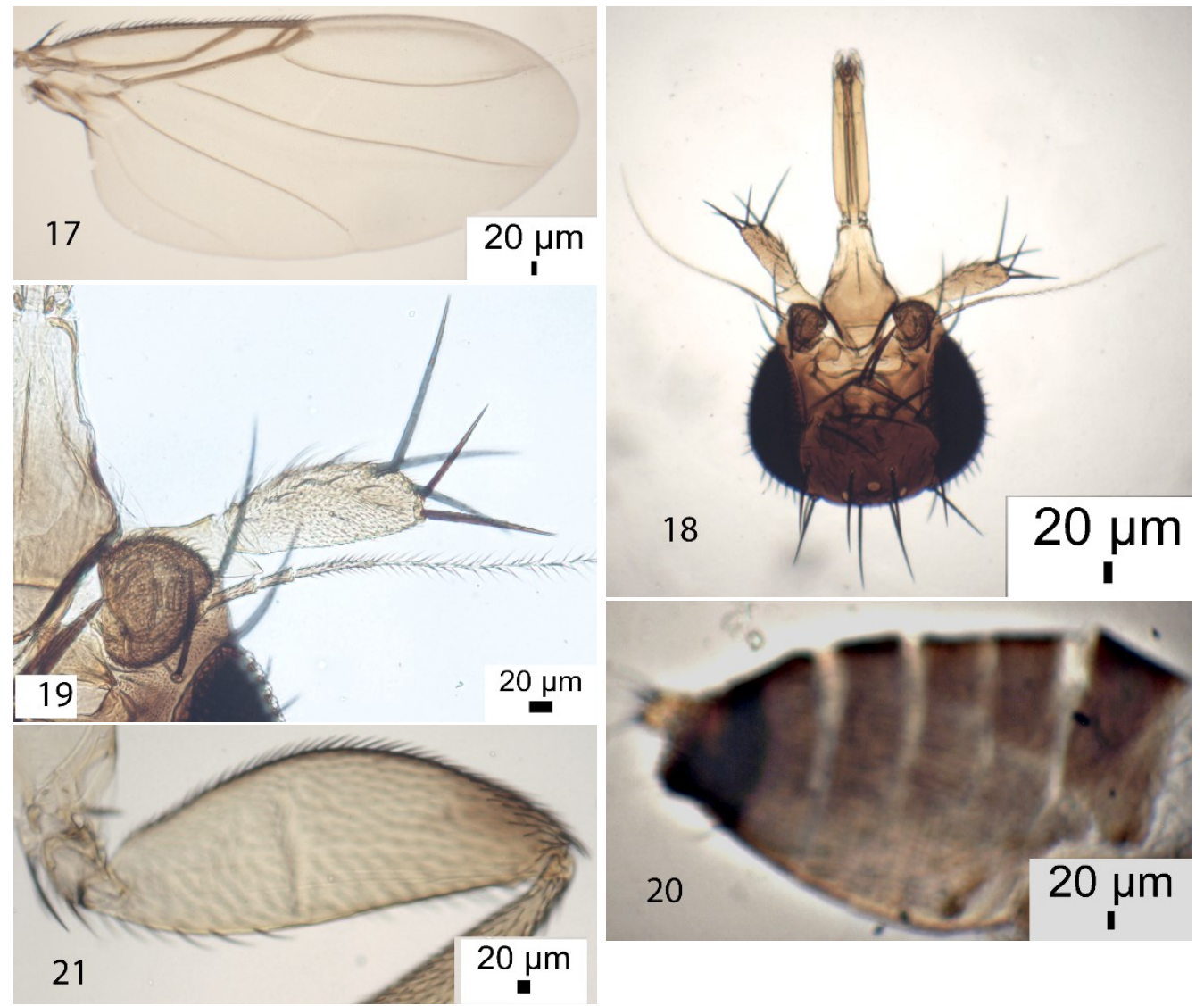

Figs 17-21. Dohrniphora guangchuni n. sp. 17 - wing, male; 18-21 - female: 18 - head; 19 - postpedicel and palp; 20 - abdomen; 21 - hind femur.

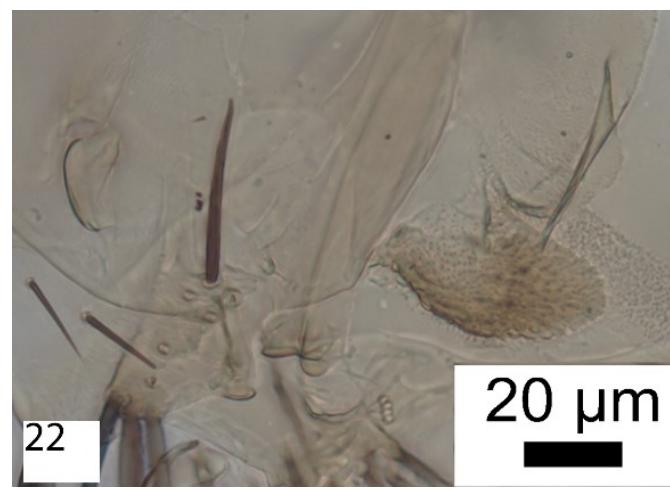

Figs 22-23. Dohrniphora leei Disney male. Hind coxal lobes.

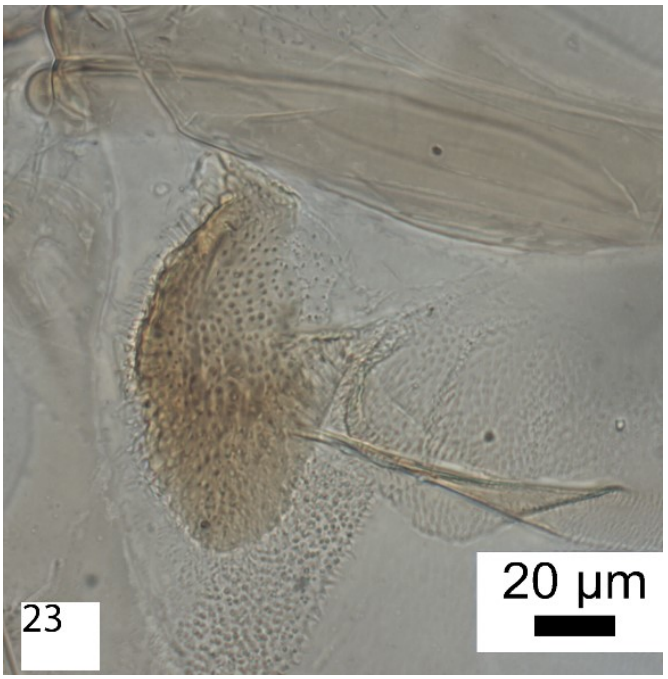


Female. Head as Fig. 18, the frons similar to male. Postpedicel and palp as Fig. 19. Abdomen as Fig. 20. Hind coxae lack the lobes of the male and hind femur (Fig. 21) in the basal half lacks the small hairs dorsally and spines ventrally and the microsculpture patch beyond. Otherwise legs similar to male and likewise the wings and halteres.

Material. Holotype male, China, Yunnan, ManNaXing Village $(10 \mathrm{~km}$ distance from Xishuangbanna Tropical Botanical Garden), Mengla, Yunnan, China, GPS: 21.875190 N, 102.277401 E, Elevation: $600 \mathrm{~m}$ a.s.1, 17 Mar 2019, at male flower of Cryptogorynae crispatula, leg. Low Shook Ling (UCMZ, 28-68). Paratypes, 3 males, 1 female, as holotype except dates 17, 22. \& 25 Mar 2019 (UCMZ, 28-68, 71, 74, 75).

Etymology. Named after Guangchun Liu, in recognition of his many valuable contributions to our knowledge of Chinese Phoridae.

\section{Megaselia Rondani}

The literature on this giant genus is very extensive. For the Oriental Region the starting point are the keys of Borgmeier $(1967 \mathrm{a}, \mathrm{b})$, including a key to "Plastophora" species and a 'Pericyclocera' - 1967b - which are now included in Megaselia. Where subsequently added species run to a couplet in these keys the relevant publications are cited below. Additional Chinese species are also described by Fang \& Liu (2005a, 2005b, 2012, 2015, Fang, Hai \& Liu 2009, Fang, Xia \& Liu 2009).

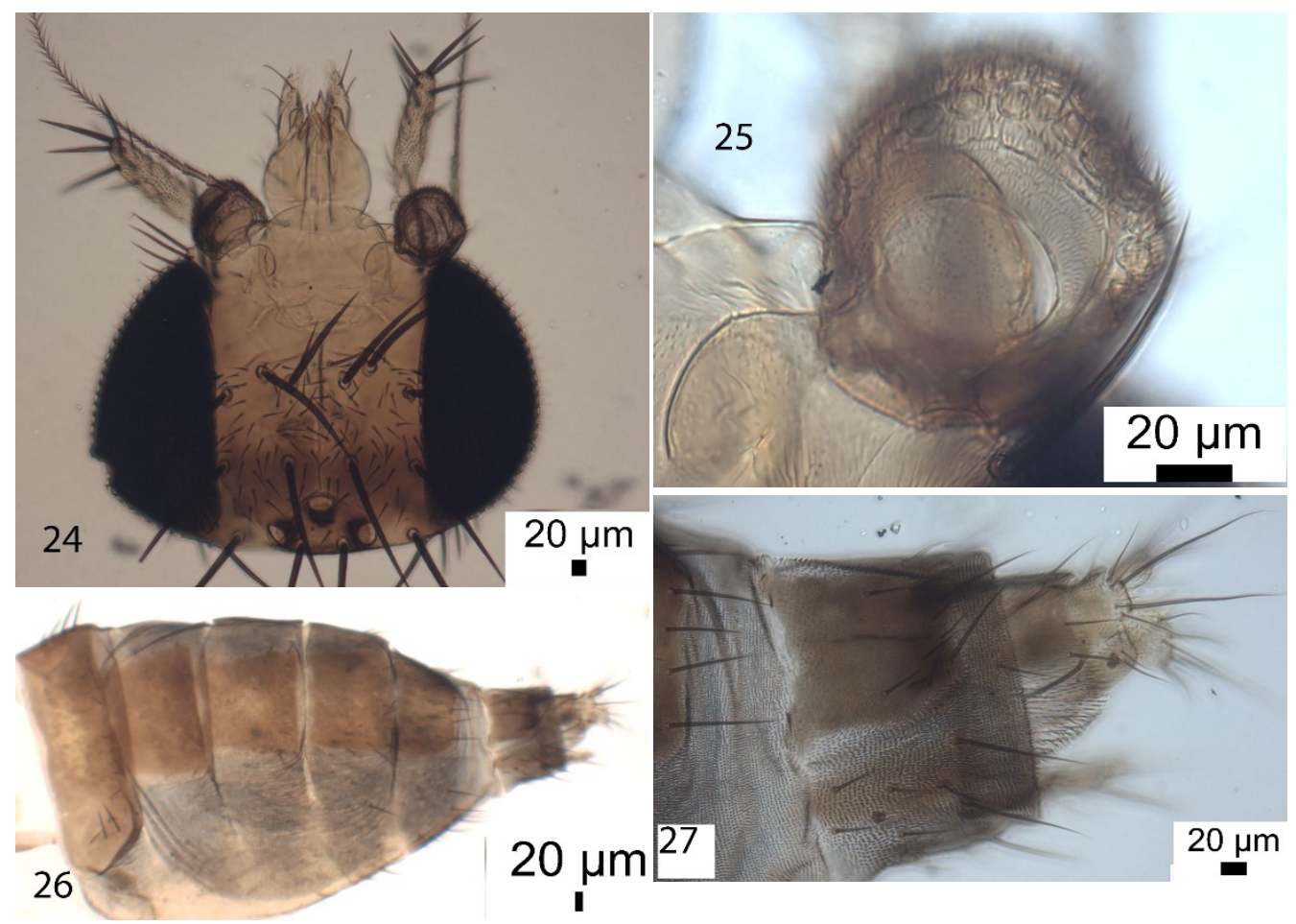

Figs 24-27. Megaselia chippensis (Brues) female; 24 - head; 25 - postpedicel; 26 - abdomen; 27 - tergite 7 to tip of abdomen. 

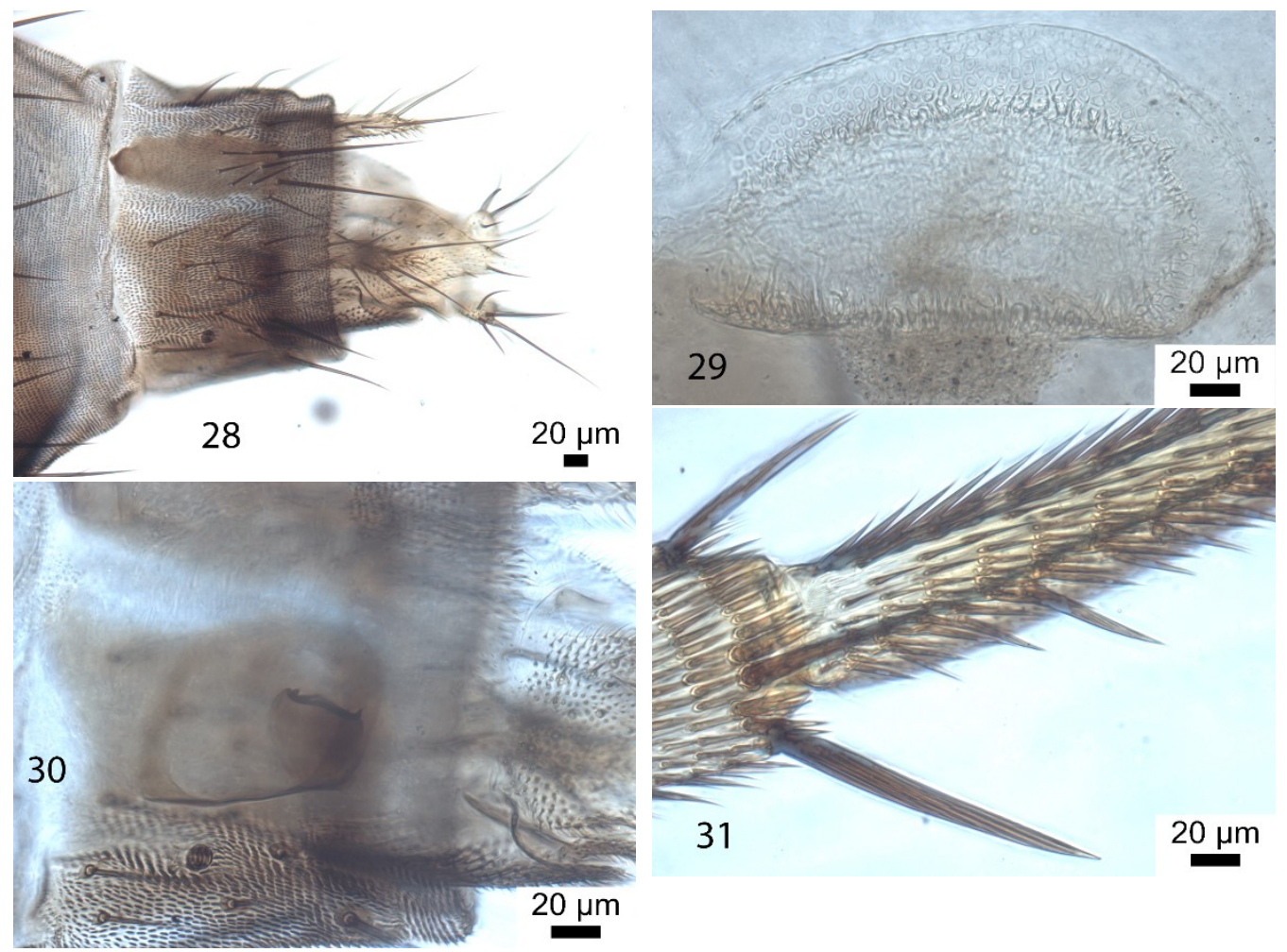

Figs 28-31. Megaselia chippensis (Brues) female; 28 - sternite 7 to tip of abdomen; 29 - Dufour's crop mechanism; 30 - furca; 31 - tip of hind tibia.

\section{Megaselia chippensis (Brues, 1911)}

(Figs 24-31)

This species was described from a single female from Taiwan. The following figures supplement the original description.

Description. Fe male. Fig. 24, head; Fig. 25, postpedicel; Fig. 26, abdomen; Fig. 27, tergite 7 to tip of abdomen; Fig. 28, sternite 7 to tip of abdomen; Fig. 29, Dufour's crop mechanism; Fig. 30, furca; Fig. 31, tip of hind tibia.

Material. Female, China, ManNaXing Village $(10 \mathrm{~km}$ distance from Xishuangbanna Tropical Botanical Garden), Mengla, Yunnan, GPS: 21.859876 N, 101.272633 E, Elevation: 600 m a.s.l., at female flower of Cryptogorynae crispatula, 22 Mar 2019, leg. Low Shook Ling (UCMZ, 28-77).

\section{Megaselia duolobata $\mathbf{n}$. sp.}

(Figs 32-44)

Diagnosis. In the key of Borgmeier (1967b) to Group VII it runs to couplet 54 lead1 M. semihyalina Beyer or couplet 57 lead 2 M. lureiclava Borgmeier. M. semihyalina was described from the female only, but I was able to remount on a slide a 'paratype' male in the Queensland Museum. While very similar to the new species it is immediately distinguished by its lack of SPS vesicles in the postpedicels. The male of M. lureiclava has a longer wing (2.0 
$\mathrm{mm}$ ) but is readily distinguished by its lack of a notopleural cleft and its short hairs below the basal half of the hind femur. The subsequently described M. shiyiluae Disney (Disney, Li \& Li, 1997 ) is very similar but its thorax is entirely brown and its antial bristles on the frons are almost directly below the anterolateral bristles.

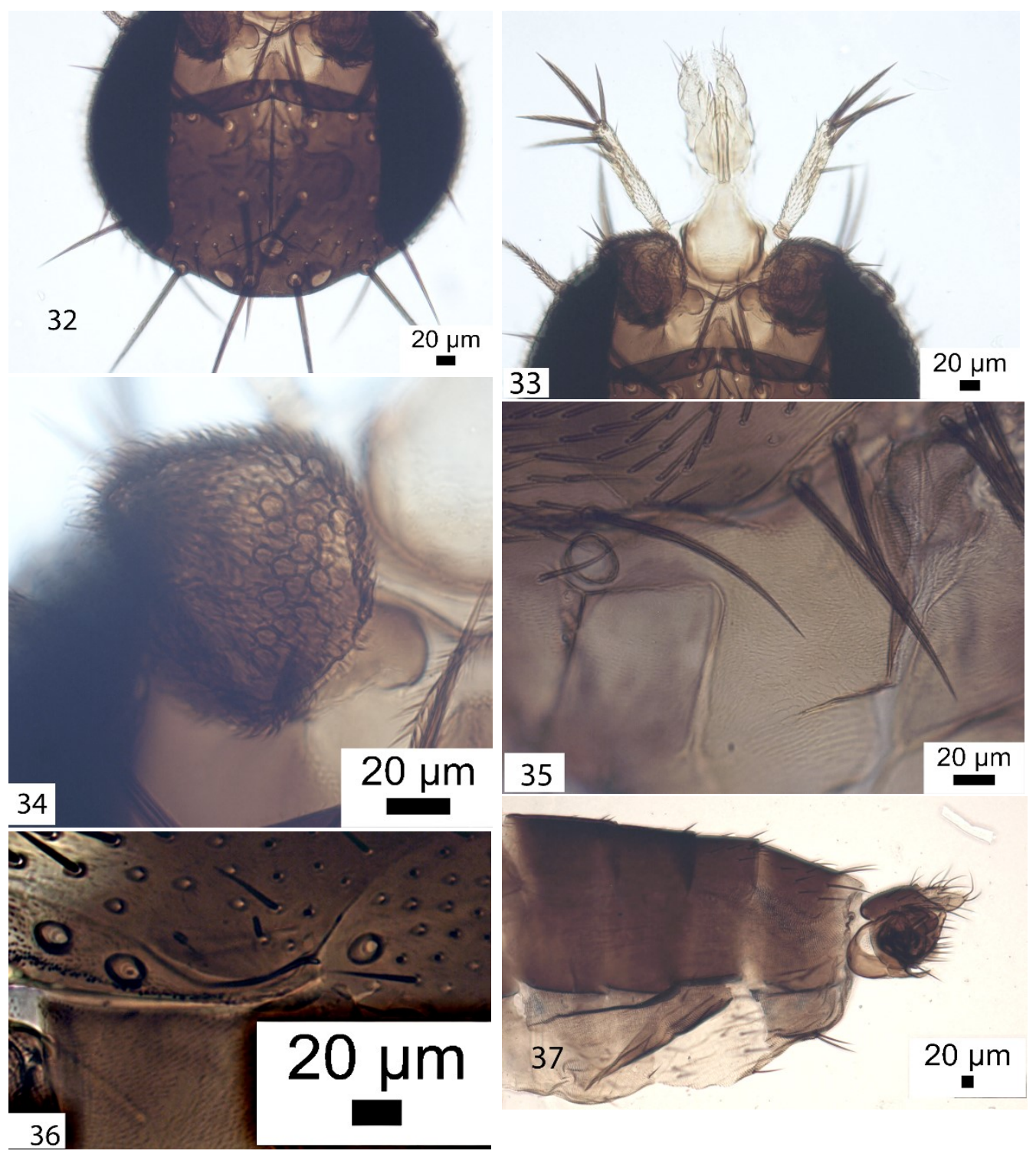

Figs 32-44. Megaselia duolobata n. sp. male. 32 - frons; 33 - antennae, palps and proboscis; 34 - postpedicel; 35 - side of thorax; 36 - notopleuron showing cleft; 37 - abdomen.

Description. Male. Frons as Fig. 32, with dense but very fine microtrichia. Cheek with 2 bristles and jowl with 2 that are longer and more robust. Proboscis, palps and proboscis as Fig. 33, the postpedicels with SPS vesicles (Fig. 34). Thorax yellowish brown scutum, brown scutellum but pale yellow on sides. Two notopleural bristles plus a cleft in front of these (Figs 
$35 \& 36$ ). Mesopleuron bare. Scutellum with an anterior pair of short hairs and a posterior pair of bristles. Abdominal tergites brown with bristles longest at rear of tergite 6 and venter pale with hairs on segments 3-6 (Fig. 37). Hypopygium as Figs 38-40). Legs pale yellow. Fore tarsus (Fig. 41) with posterodorsal hair palisade on segments 1-4 and 5 longer than 4. Dorsal hair palisade of mid tibia extends about 0.74 times its length. Hairs below basal half of hind femur longer than those of anteroventral row of outer half (Fig. 42). Hind tibia with about 10 differentiated posterodorsals of which 5 are robust and the most apical is longer than these,
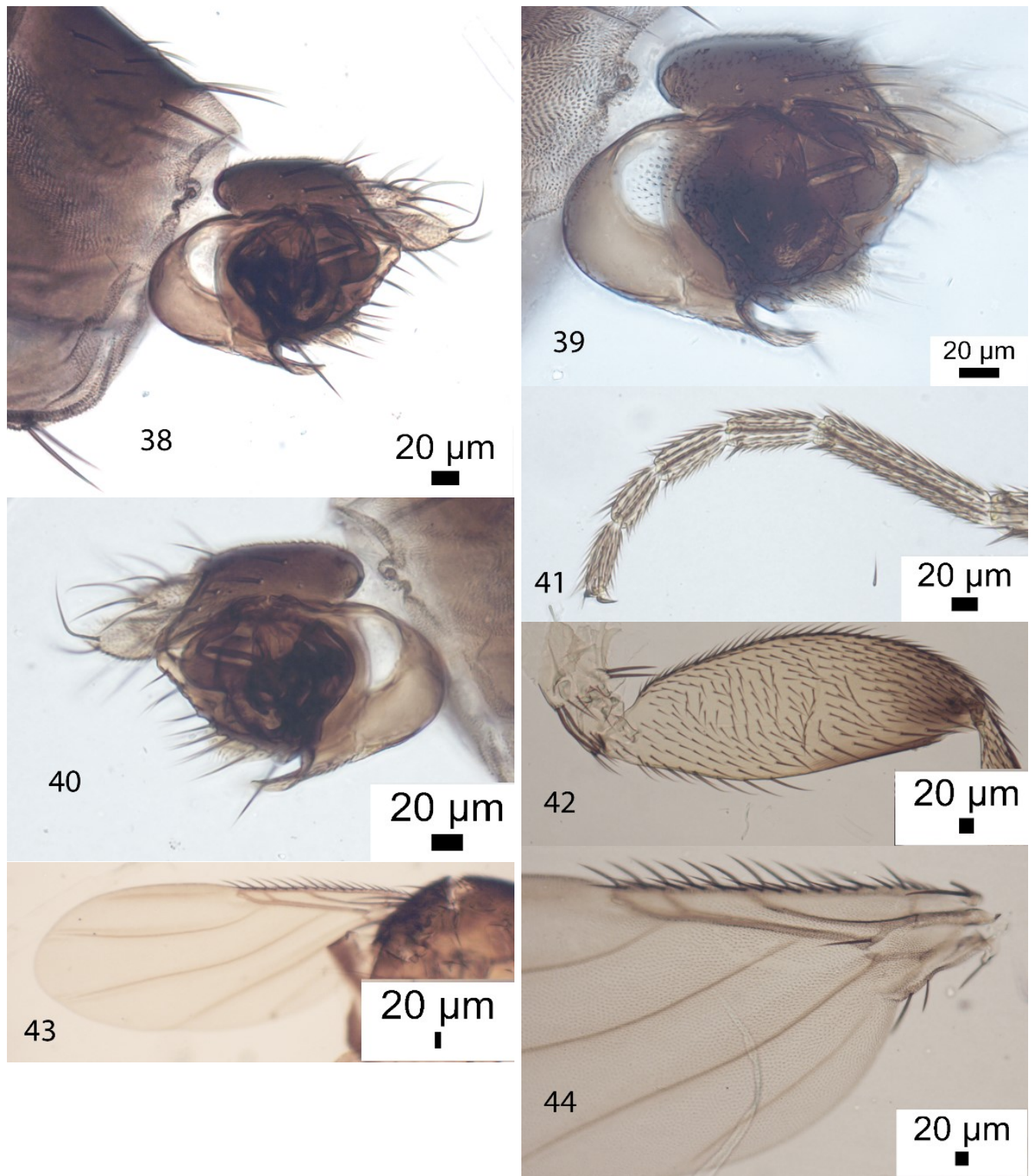

Figs 32-44. Megaselia duolobata n. sp. male. 38 - left face of hypopygium; 39 - left face of hypandrium and penis complex; 40 - right face of hypopygium; 41 - front tarsus; 42 - hind femur, 43 - wing; 44 - basal half of wing. 
without anterodorsals, and spinules of apical combs unforked. Wings (Figs 43 \& 44) $1.13 \mathrm{~mm}$ long. Costal index 0.46. Costal ratios $3.6: 2.0: 1$. Costal cilia (of section 3) $0.07 \mathrm{~mm}$ long. Vein 3 hair $0.08 \mathrm{~mm}$ long. 2 axillary bristles, the outermost being $0.07 \mathrm{~mm}$ long. Sc absent. Haltere pale.

Material. Holotype male, China, Yunnan, ManNaXing Village $(10 \mathrm{~km}$ distance from Xishuangbanna Tropical Botanical Garden), Mengla, Yunnan, China, GPS: 21.875190 N, 102.277401 E, Elevation: $600 \mathrm{~m}$ a.s.1, 17 Mar 2019, at male flower of Cryptogorynae crispatula, leg. Low Shook Ling (UCMZ, 28-66).

Etymology. Named after the two well developed hypandrial lobes (duolobata).

\section{Megaselia excrispatulae n. sp.}

(Figs 45-56)

Diagnosis. In the key of Borgmeier (1967b) to Group VII it runs to couplets 68 lead 1 M. antialis Borgmeier, but its hypopygium is clearly different (despite its 'long' anal tube, which is $0.13 \mathrm{~mm}$ long). It clearly belongs to the M. angusta (Wood) complex, whose European species were last reviewed in Disney (1999a), but further review of this complex is currently in preparation. In this (1999) key it runs to couplet 2 lead 1 M. pulicaria (Fallén) but its hypopygium (with it anal tube shorter than the epandrium) excludes this species. The new species most closely resembles that of $M$. interstinctus that is described below, but the all brown abdominal tergites and all pale hind femora immediately distinguish it.

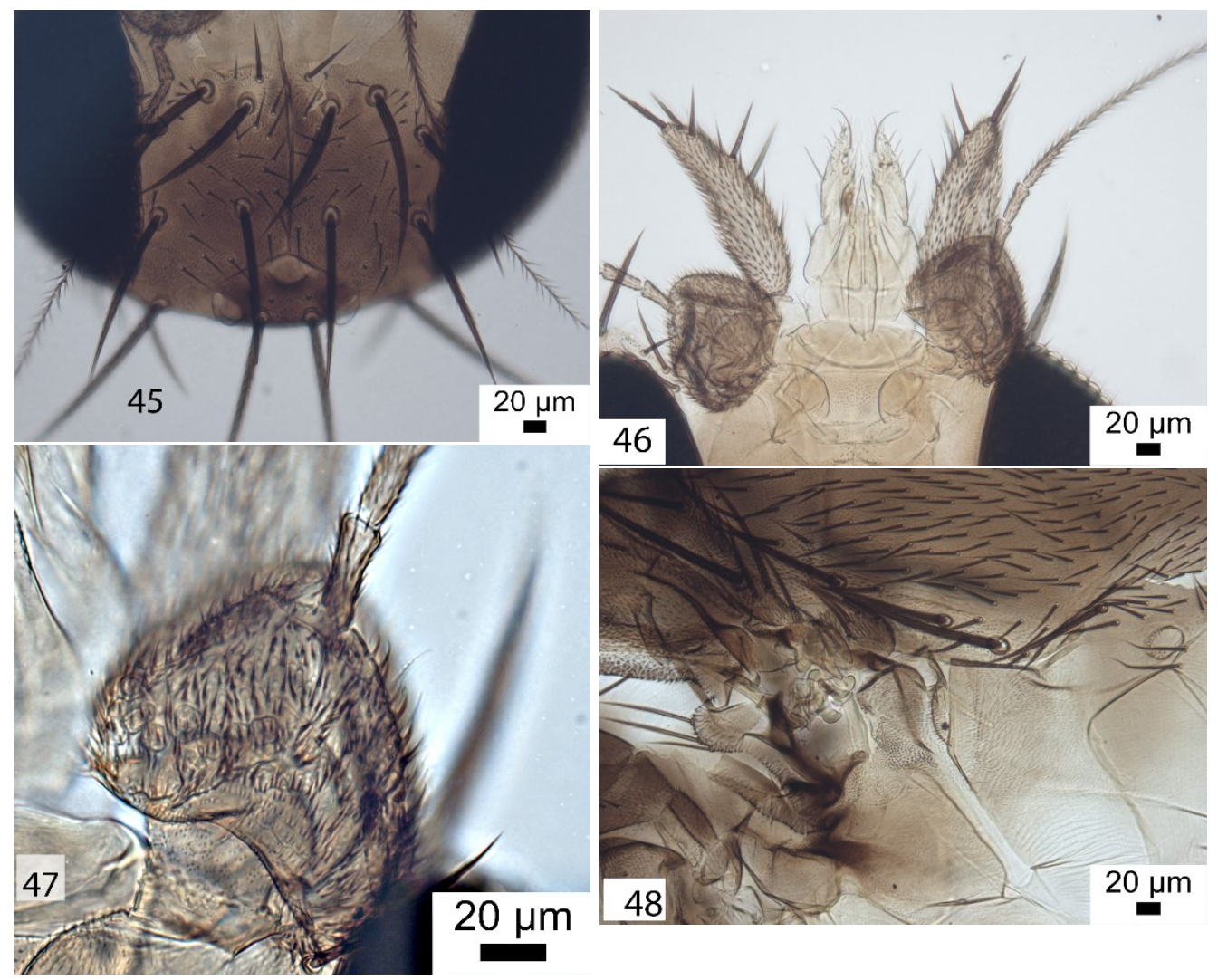

Figs 45-48. Megaselia excrispatulae n. sp. male. 45 - frons; 46 - antennae, palps and proboscis; 47 - postpedicel; 48 notopleuron and mesopleuron. 


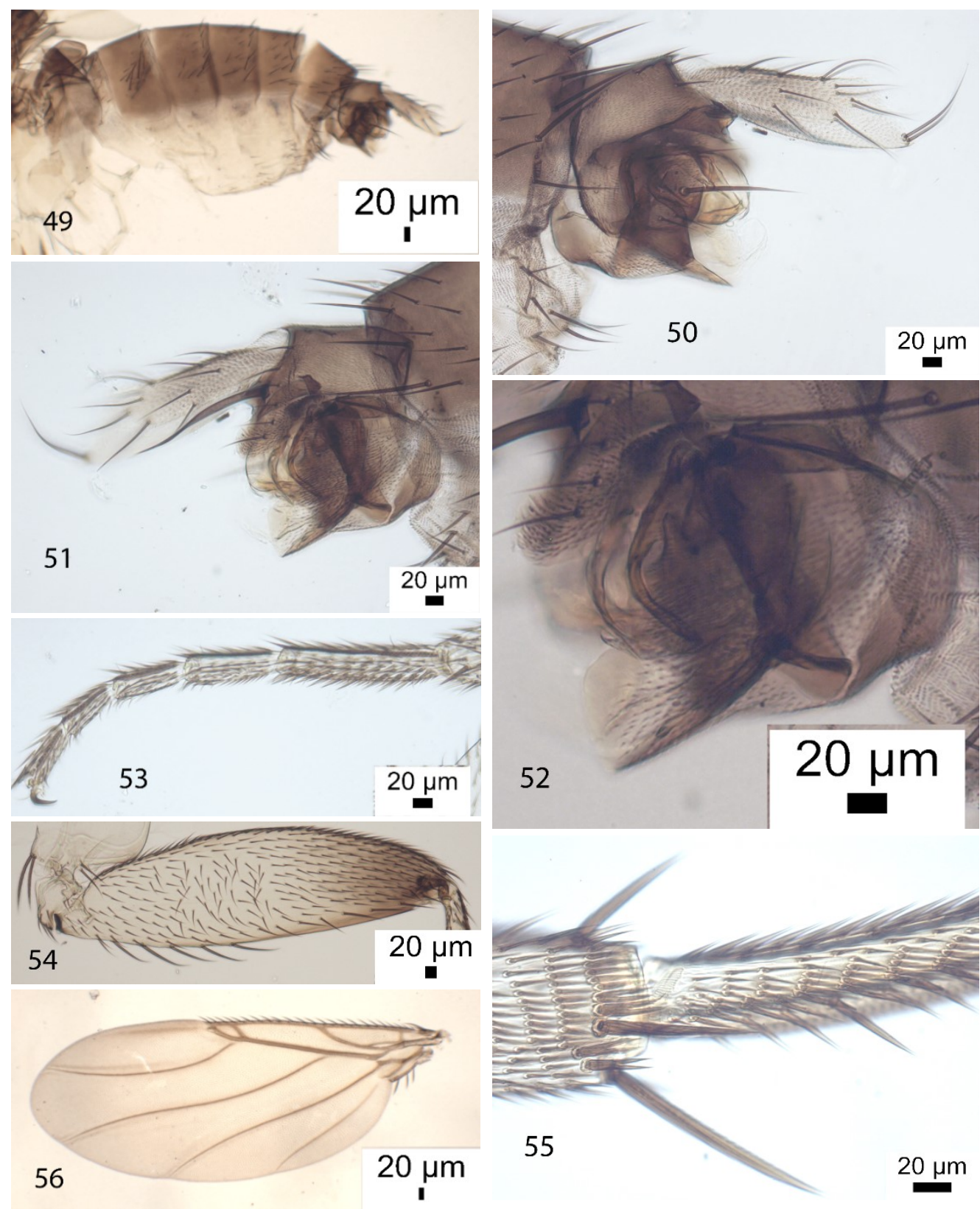

Figs 49-56. Megaselia excrispatulae n. sp. male. 49 - side of abdomen; 50 - left face of hypopygium; 51 - right face of hypopygium; 52 - left face of hypandrium; 53 - front tarsus; 54 - hind femur; 55, - tip of hind tibia; 56, -wing.

Description. Male. Frons as Fig. 45, with dense but very fine microtrichia. Cheek with 3 bristles and jowl with 2 that are longer and more robust. Antennae, palps and proboscis as Fig. 46, the postpedicels with pale SPS vesicles (Fig. 47). Thorax brown above but pale at sides. With 2 notopleural bristles and no cleft in front of these (Fig. 48). Mesopleuron bare. Scutellum with an anterior pair of short hairs and a posterior pair of bristles. Abdominal tergites brown, venter 
pale with hairs on segments 3-6 (Fig. 49. Hypopygium as Figs 50-52, with anal tube being 0.24 mm long. Legs whitish yellow. Fore tarsus (Fig. 53) with posterodorsal hair palisade on segments 1-5 and 5 longer than 4. Dorsal hair palisade of mid tibia extends about $0.78-0.79$ times its length. Hairs below basal half of hind femur longer than those of anteroventral row of outer half (Fig. 54). Hind tibia with about 10 differentiated posterodorsals of which 4 are robust and the most apical is longer than these, without anterodorsals, and spinules of apical combs forked (Fig. 55). Wings (Fig. 56) 1.58-1.65 mm long. Costal index 0.51-0.54. Costal ratios 2.4-3.8 : 3.94.3 : 1. Costal cilia (of section 3 ) $0.06 \mathrm{~mm}$ long. Vein 3 hair $0.03 \mathrm{~mm}$ long or absent. 4 axillary bristles, the outermost being $0.07-0.08 \mathrm{~mm}$ long. Sc reaching R1. Haltere brown.

Material. Holotype male, China, Yunnan, ManNaXing Village $(10 \mathrm{~km}$ distance from Xishuangbanna Tropical Botanical Garden), Mengla, Yunnan, China, GPS: 21.875190 N, 102.277401 E, Elevation: 600 m a.s.1, 22 Mar 2019, at male flower of Cryptogorynae crispatula, leg. Low Shook Ling (UCMZ, 28-70). Paratype male, as holotype except (UCMZ, 28-76).

Etymology. Named after being caught from (ex) the flower of Cryptogorynae crispatula.
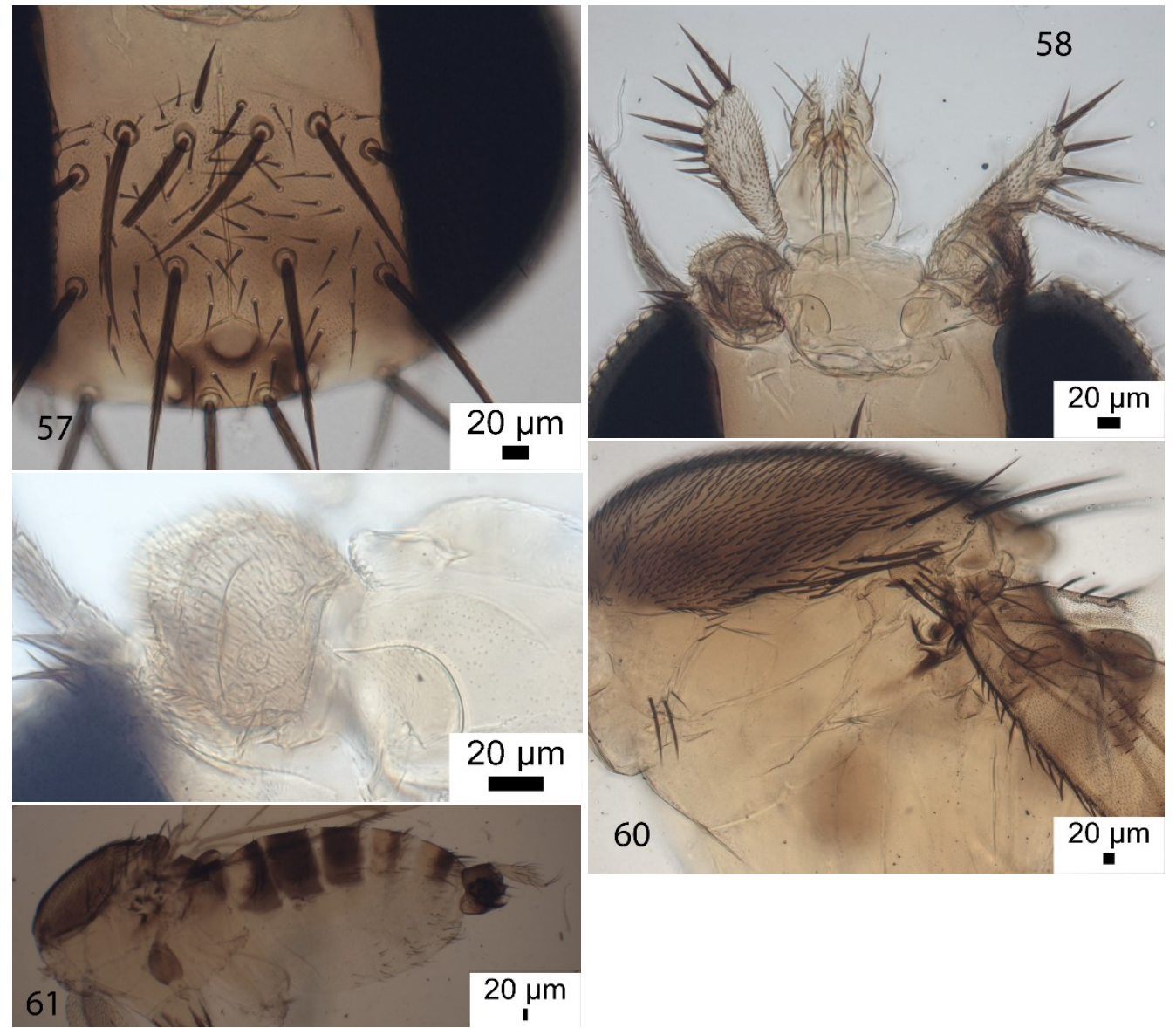

Figs 57-61. Megaselia interstinctus n. sp. male. 57 - frons; 58 - postpedicels, palps and proboscis; 59 - postpedicel; 60 - side of thorax, 61 - side of thorax and abdomen. 


\section{Megaselia interstinctus n. sp.}

(Figs 57-78)

Diagnosis. In the key of Borgmeier (1967b) to Group VII it runs to couplets 74 lead $1 \mathrm{M}$. versicolor Borgmeier. But its hypopygium differs, with its dorsal face of the epandrium clearly shorter than its lower edge; and the females abdominal tergites 2 and 6 entirely yellow. However, two species from the Seychelles and a species from Saudi Arabia closely resemble this species (Disney, 2006, 2009). Their male abdominal tergites 5 and 6 are entirely yellow but in the new species they are part brown part yellow. The number of hairs on the frons of M. consueta (Collin) exceeds 100 but are far fewer in M. falloconsueta Disney, M. dawahi Disney and the new species. It clearly belongs to $M$. angusta (Wood) complex, whose European species were last reviewed in Disney (1999a), but further review of his complex is currently in preparation. In this 1999 review it runs to its subgroup characterised by forked spinules in the comb at the tip of the hind tibia. Its costal ratios, general yellowish colour and hypopygium distinguish it from the rest of this subgroup.

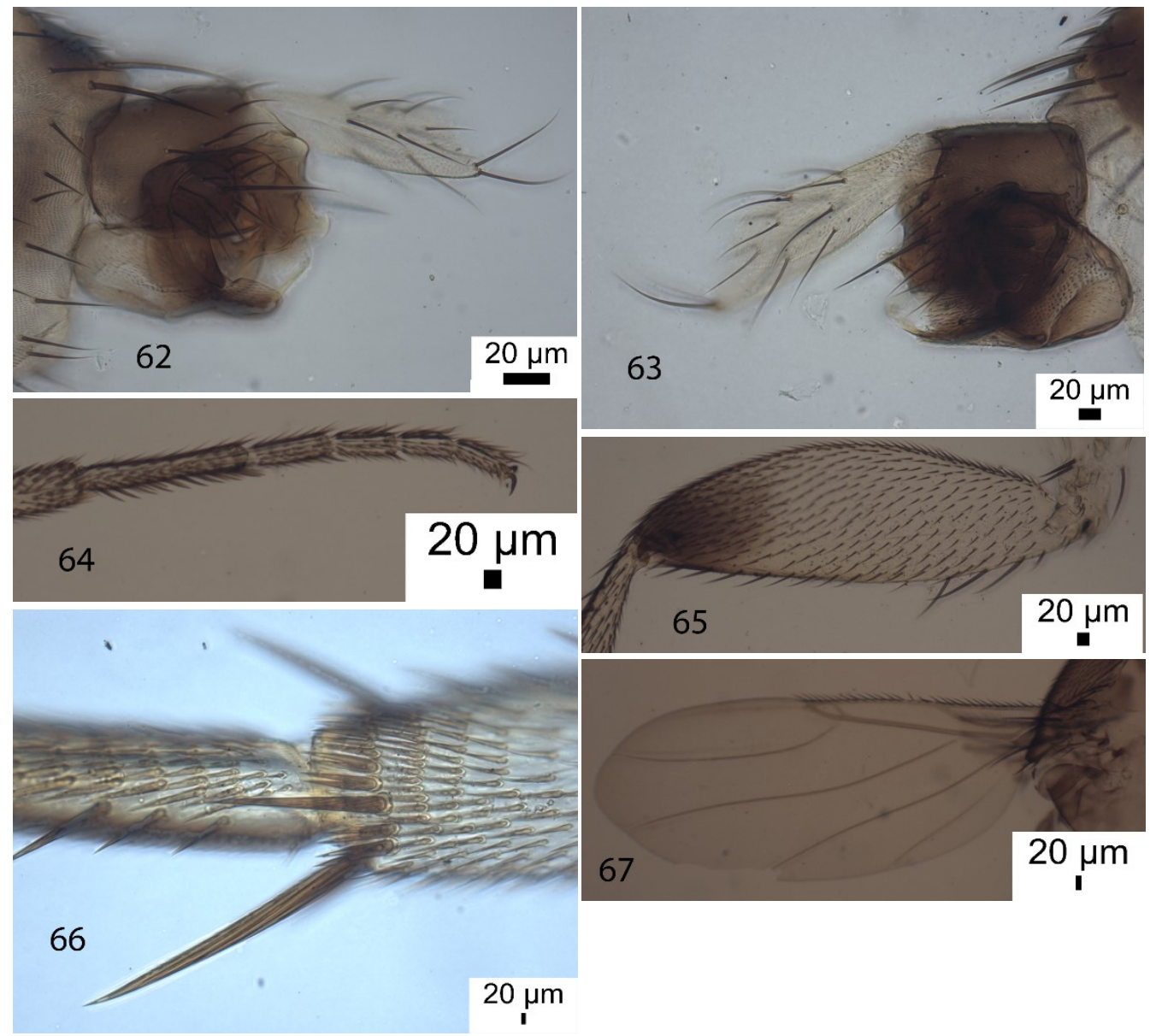

Figs 62-67. Megaselia interstinctus n. sp. male; $62 \& 63$ - left and right faces of hypopygium; 64 - front tarsus; 65 hind femur; 66 - tip of hind tibia; 67 - wing. 


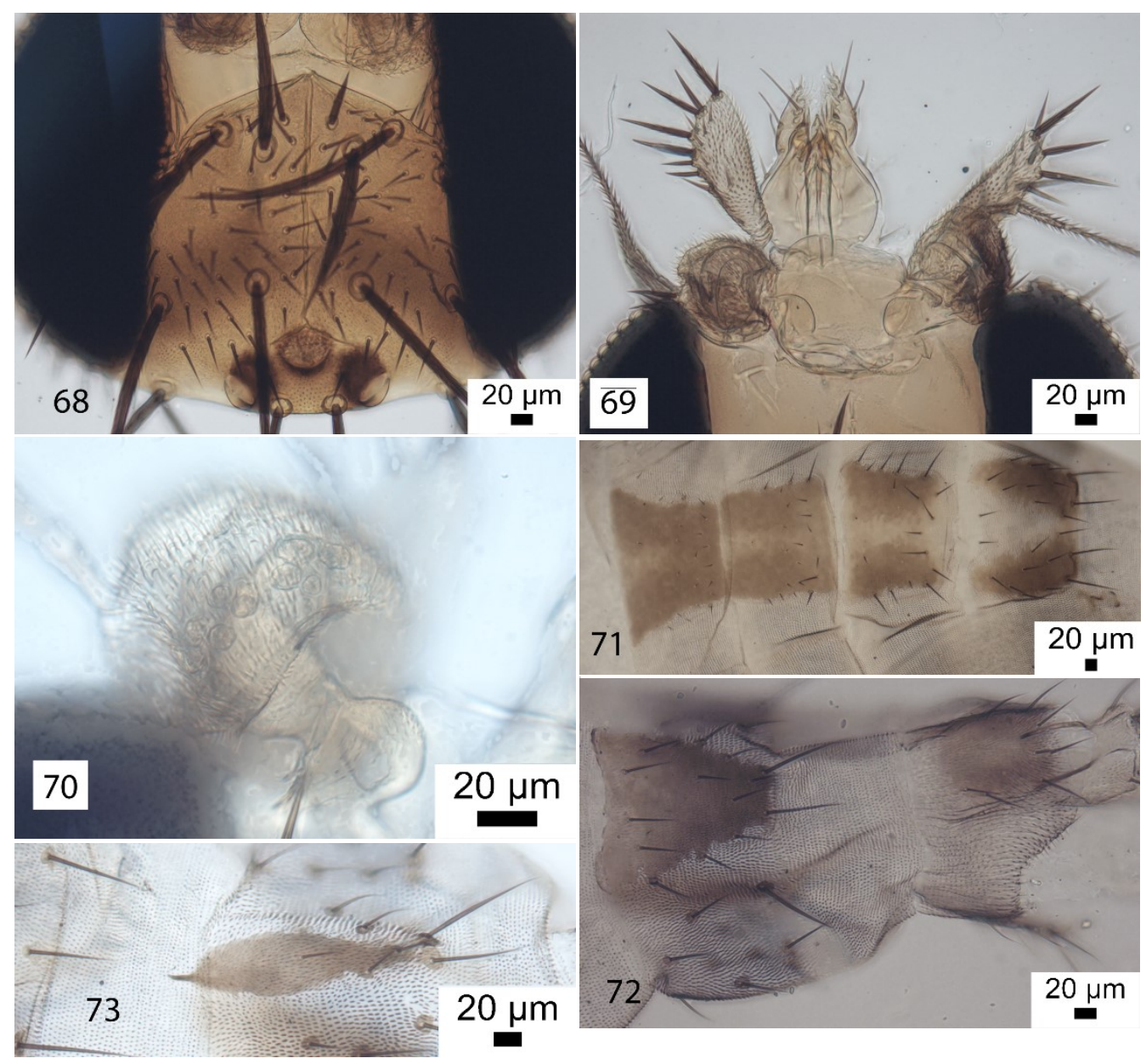

Figs 68-73. Megaselia interstinctus n. sp. female. 68 - frons; 69 - antennae, palps and proboscis; 70 - postpedicel; 71 abdominal tergites $3-6 ;-72$, tergites 7 and $8 ; 73$ - sternite 7 .

Description. Male. Frons as Fig. 57, with dense but very fine microtrichia. Cheek with 4 bristles and jowl with 2 that are much longer and more robust. Postpedicels with SPS vesicles (Fig. 59), palps and proboscis as Fig. 58. Thorax as Fig. 51, with 2 notopleural bristles, and no cleft in front of these, and mesopleuron bare. Scutellum with an anterior pair of small hairs and a posterior pair of bristles. Abdominal tergite 2 about as long as T3 but about twice as wide. Abdomen and venter as Fig. 61. Hypopygium as Figs $62 \& 63$, the right hypandrial lobe being shorter than the left. Legs yellow apart from brown tips to hind femora. Fore tarsus (Fig. 64) with posterodorsal hair palisade on segments $1-5$ and 5 longer than 4 . Dorsal hair palisade of mid tibia extends about $0.74-0.77$ its length. Hairs below basal half of hind femur longer than those of anteroventral row of outer half (Fig. 65). Hind tibia with 6-8 differentiated posterodorsal hairs, without anterodorsals, and spinules of apical combs forked (Fig. 66). Wings (Fig. 67) 1.1$1.7 \mathrm{~mm}$ long. Costal index 0.54-0.58. Costal ratios 3.4-3.9:4.3-5.2:1. Costal cilia (of section 3) $0.05 \mathrm{~mm}$ long. Vein 3 with $0-1$ hairs at base, when present only $0.03 \mathrm{~mm}$ long. 2-3 axillary bristles, the outermost being $0.05 \mathrm{~mm}$ long. Sc reaching R1. Haltere knob brown (Fig. 61). 


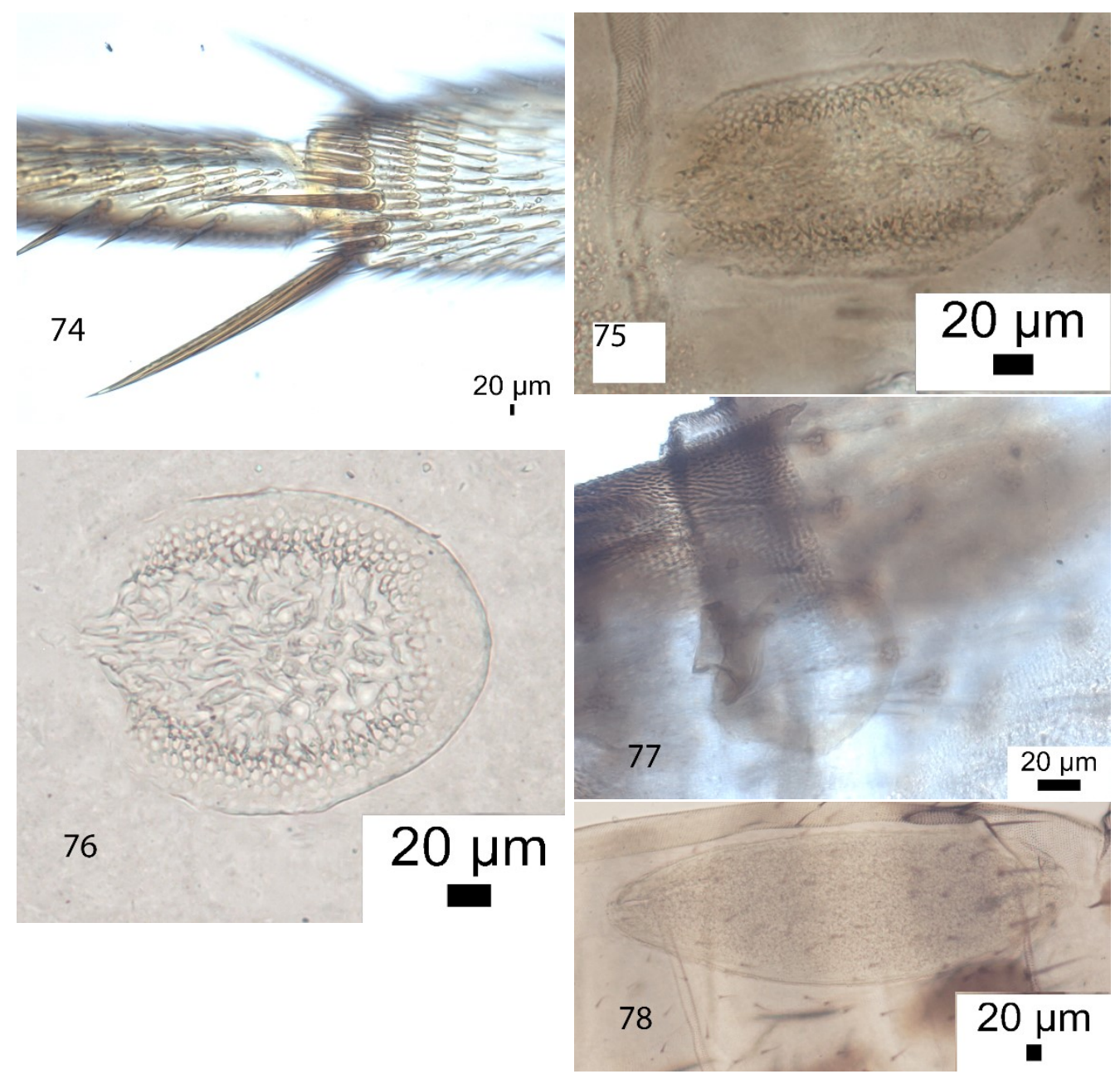

Figs 74-78. Megaselia interstinctus n. sp. female; 74 - tip of hind tibia; 75 - typical Dufour's crop mechanism; 76 atypical DCM; 77 - furca; 78 - egg.

Female. Frons as Fig. 68, antennae, palps and proboscis as Fig. 69. Postpedicel as Fig. 70. Abdominal tergites 3 to 6 as Fig. 71. Tergite 2 has 1-2 loner bristles each side and 0-2 smaller bristles. Tergites 7 and 8 as Fig. 72. Sternite 7 as Fig. 73. Sternum 8 to tip of abdomen as Fig. 74. Dufou's crop mechanism typically as Fig. 75, but a little variable (Fig. 76). Furca as Fig. 77. An egg as Fig. 78. Wing similar to male but larger at $1.6-1.8 \mathrm{~mm}$ long. Costal index $0.54-0.55$. Costal ratios $3.0-3.8: 3.9-4.6: 1$. Costal cilia $0.05 \mathrm{~mm}$ long $2-3$ axillary bristles, the outermost being $0.08 \mathrm{~mm}$ long.

Material. Holotype male, China, Yunnan, ManNaXing Village $(10 \mathrm{~km}$ distance from Xishuangbanna Tropical Botanical Garden), Mengla, Yunnan, China, GPS: 21.875190 N, 102.277401 E, Elevation: $600 \mathrm{~m}$ a.s.1, 17 Mar 2019, at male flower of Cryptogorynae crispatula, leg. Low Shook Ling (UCMZ, 28-65). Paratypes 15 males, 2 females, as holotype, 16-30 Mar 2019 (UCMZ, 28-63-79) and 13 males, 4 females not slide mounted. 1 male, 3 females, ManNaXing Village (10 km distance from Xishuangbanna Tropical Botanical Garden), Mengla, GPS: 21.859876 N, 101.272633 E, Elevation: $600 \mathrm{~m}$ a.s.1. ManNaXing Village (10 km distance 
from Xishuangbanna Tropical Botanical Garden), Mengla, Yunnan, China. GPS: 21.859876 N, 101.272633 E, Elevation: 600 m a.s.1., 22-30 Mar 2019, at female flowers (UCMZ, 28-75-79), also 6 females not slide mounted.

Etymology. Named after it being immediately separated (interstinctus) from the rest of the M. angusta (Wood) species complex.

\section{Megaselia leptotibiarum n. sp.}

(Figs 79-97)

Diagnosis. In the key of Borgmeier (1967b) to Group VII the male runs to couplets 94 lead 2, 98 lead 1 or 105 lead 2. Apart from its different hypopygium to these options, its combination of yellow legs, subcosta vein running to vein R1, short coastal cilia and SPS vesicles in its postpedicels distinguishes the species. The female runs to couplet 94 lead $1 \mathrm{M}$. obscuriterga Beyer, but it has a costal index of $0.59-0.60$, costal cilia of $0.096 \mathrm{~mm}$, and abdominal tergite 3 longer than T2, with longer hairs at the sides of $\mathrm{T} 2$.
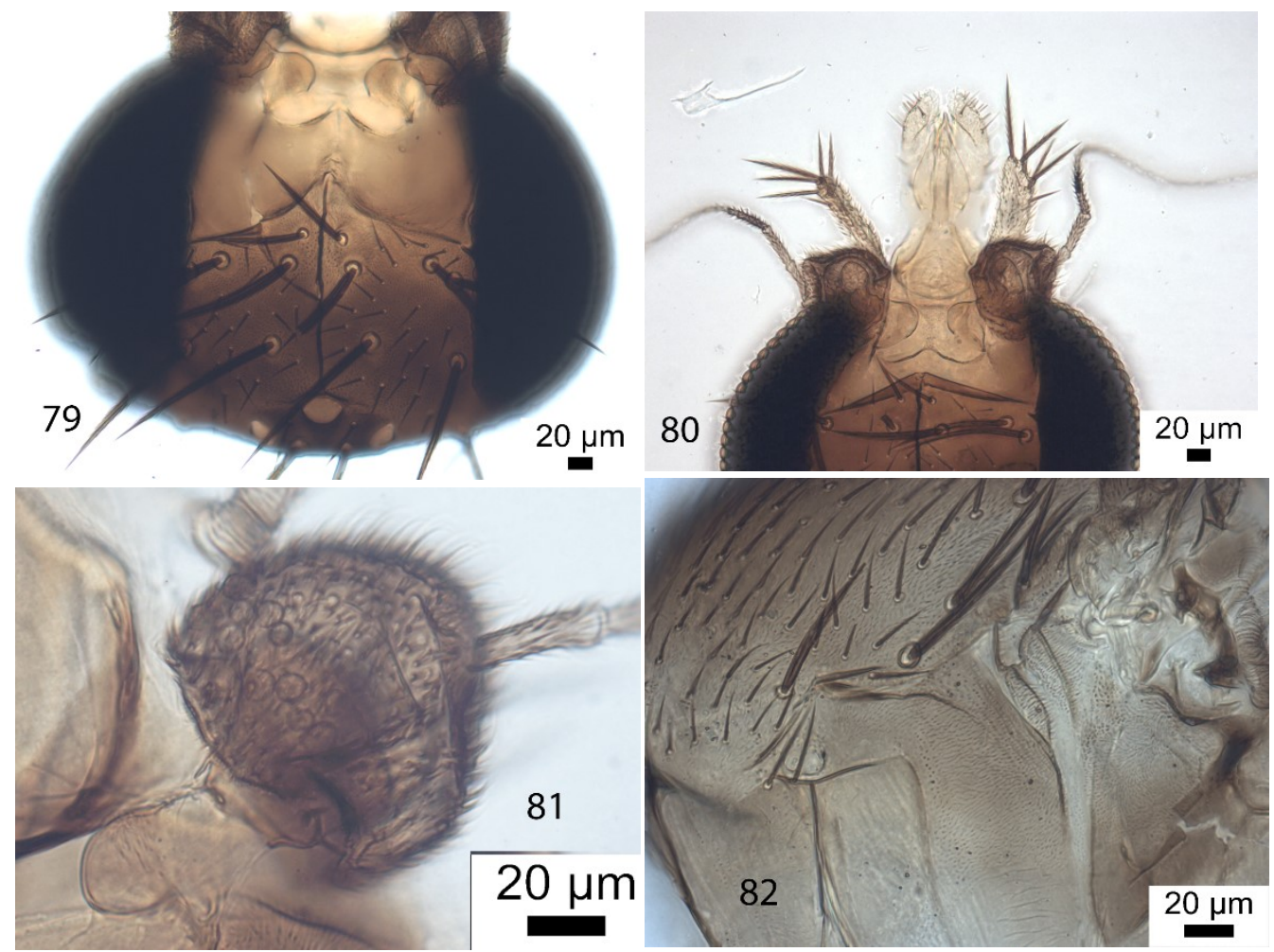

Figs 79-88. Megaselia leptotibiarum n. sp. male. 79 - frons; 80, - antennae, palps and proboscis; 81 - postpedicel; 82 side of thorax; 83 - side of thorax and abdomen; 84 - left face of hypopygium; 85 - right face of hypopygium; 86, front tarsus; 87 - hind femur; 88 , - wing.

Description. Male. Frons as Fig. 79, with dense but very fine microtrichia. Cheek with 4 bristles and jowl with 2 that are longer and more robust. Postpedicels, with SPS vesicles Fig. 81), palps and proboscis as Fig. 80. Side of thorax as Fig. 82, with 2 notopleural bristles and no cleft in front of these, and mesopleuron bare. Scutellum with an anterior pair of small hairs and a posterior pair of bristles. Abdomen as Fig. 83, the venter with hairs on segments 3-6. 
Hypopygium as Figs 84 \& 85). Legs essentially yellow. Fore tarsus (Fig. 86) with posterodorsal hair palisade on segments 1-4 and 5 longer than 4. Mid tibia somewhat thinner than usual, being $0.03-0.05 \mathrm{~mm}$ thick, compared with the basitarsus thickness of $0.02-0.03 \mathrm{~mm}$. Dorsal hair palisade of mid tibia extends about 0.63 its length. Hairs below basal half of hind femur about as long as those of anteroventral row of outer half (Fig. 87). Hind tibia with a dozen weakly differentiated posterodorsal hairs, without anterodorsals, and spinules of apical combs simple. Wings (Fig. 88) 1.0-1.4 mm long. Costal index 0.52-0.53. Costal ratios 2.2-3.5 : 1.92.8 : 1. Costal cilia (of section 3) $0.05-0.06 \mathrm{~mm}$ long. No vein 3 hair. $2-3$ axillary bristles, the outermost being $0.07-0.09 \mathrm{~mm}$ long. Sc reaching R1. Haltere knob brown (Fig. 83).

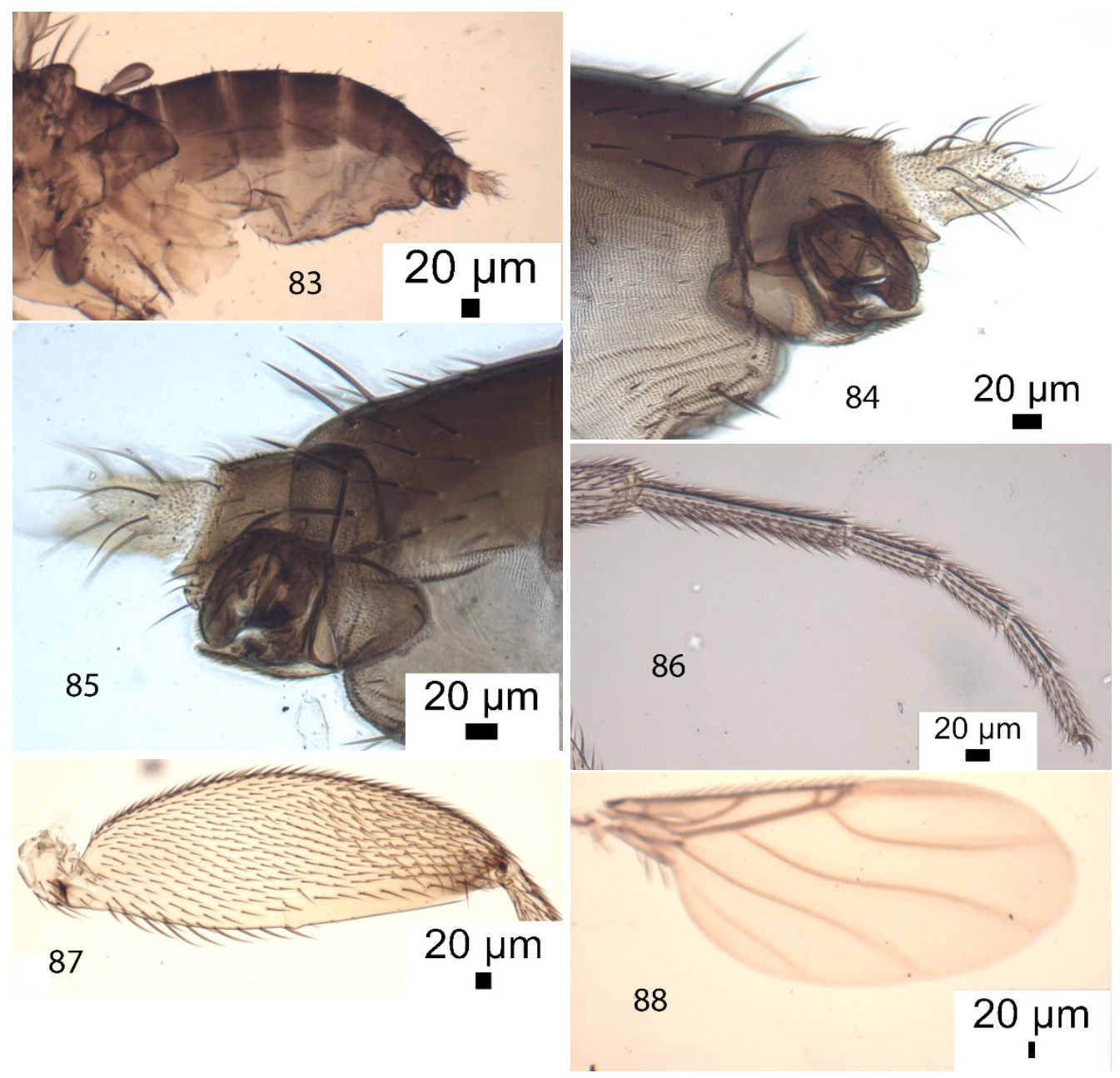

Figs 83-88. Megaselia leptotibiarum n. sp. male; 83 - side of thorax and abdomen; 84 - left face of hypopygium; 85 right face of hypopygium; 86, - front tarsus; 87 - hind femur; 88, - wing.

Female. Frons as Fig. 89. Postpedicels, palps and proboscis as Fig. 90. Postpedicel as Fig. 91. Abdominal tergite 7 as Fig. 92. Segment 7 to tip of abdomen as Fig. 93. sternite 7 as Fig. 94. Dufour's crop mechanism as Figs 95 \& 96. An egg as Fig. 97. 

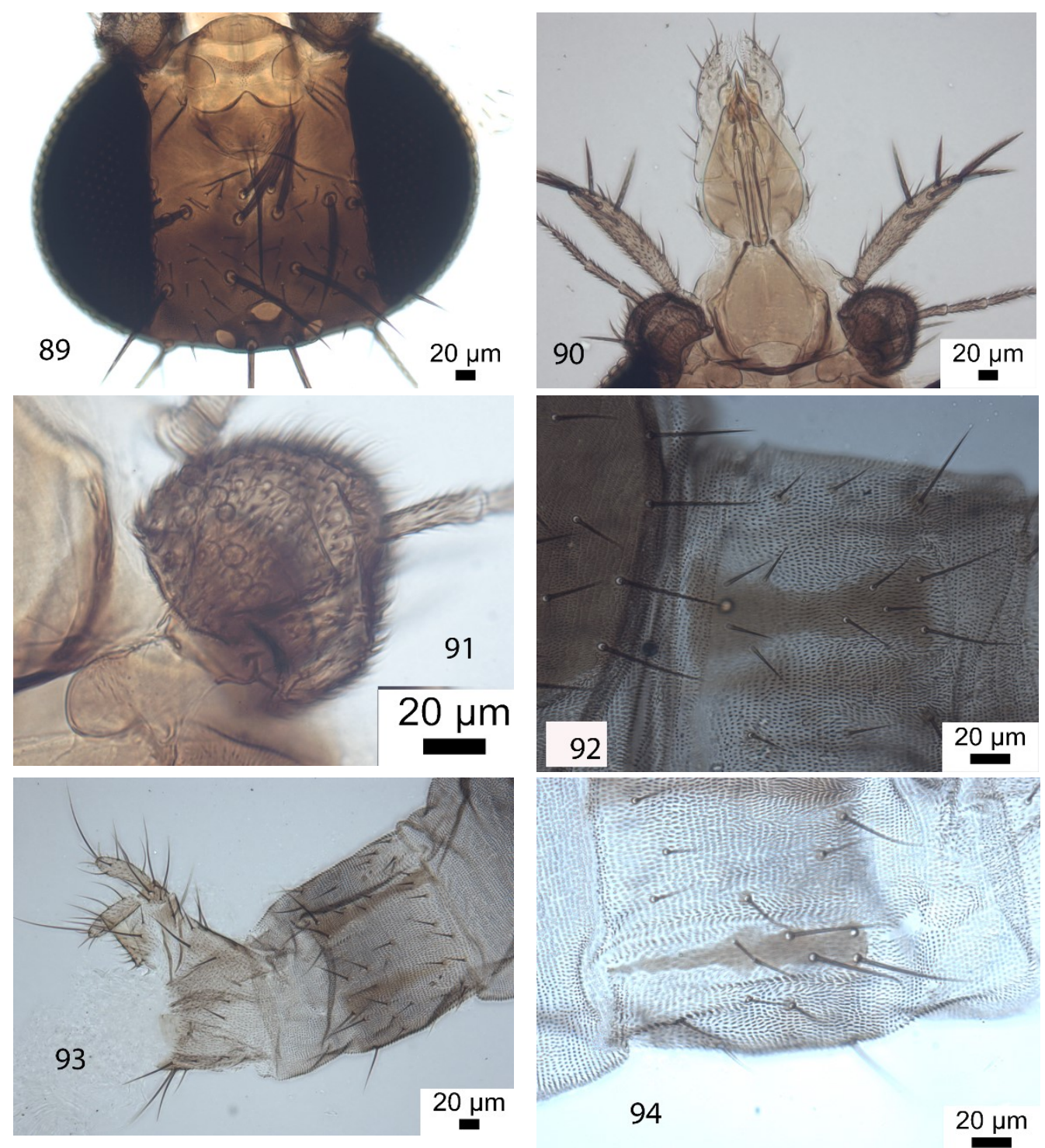

Figs 89-94. Megaselia leptotibiarum n. sp. Female; 89 - frons; 90 - antennae, palps and proboscis; 91 - postpedicel; 92 - tergite 7; 93 - segment 7 to tip of abdomen; 94 -sternite 7.

Material. Holotype male, China, Yunnan, ManNaXing Village $(10 \mathrm{~km}$ distance from Xishuangbanna Tropical Botanical Garden), Mengla, GPS: 21.875190 N, 102.277401 E, Elevation: $600 \mathrm{~m}$ a.s.1, 16 Mar 2019, at male flower of Cryptogorynae crispatula, leg. Low Shook Ling (UCMZ, 28-64). Paratypes, 11 males, 8 females as holotype except dates 16, 17 \& 22 Mar 2019 (UCMZ, 28-63-79). Also 11 males, 10 females not slide mounted. Paratype 1 female, 25 Mar 2019, ManNaXing Village (10 km distance from Xishuangbanna Tropical Botanical Garden), Mengla, Yunnan, China. GPS: 21.859876 N, 101.272633 E, Elevation: 600 $\mathrm{m}$ a.s.1., at male flower of Cryptogorynae crispatula, 16 Mar 2019, leg. Low Shook Ling (UCMZ, 28-64). Also 17 males, 15 females not slide mounted.

Etymology. Named after the very slender (lepto) mid tibiae. 


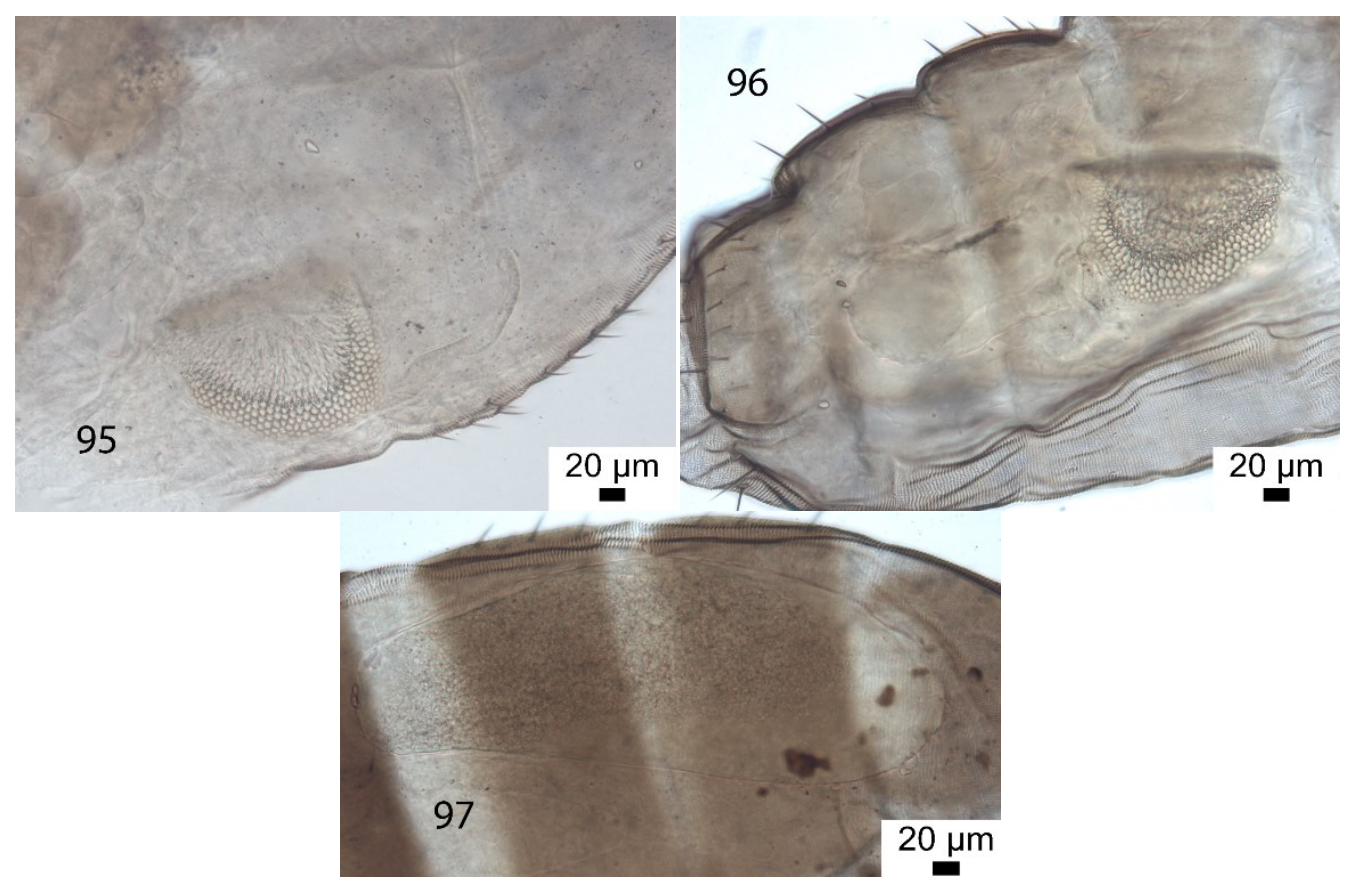

Figs 95-97. Megaselia leptotibiarum n. sp. female; 95-96 - Dufour's crop mechanism; 97 - egg.

\section{Megaselia menglaensis n. sp.}

(Figs 98-109)

Diagnosis. In the key of Borgmeier (1967b) to Group VII it runs to couplet 74 , its hypopygium fits neither option. The subsequently described M. belumensis Disney runs to this couplet, but its hind femur is yellow with a contrasting brown tip and its epandrium has several long bristle-like hairs. Otherwise it most closely resembles M. interstictus (described above) apart from the latter's hind femur being yellow with a contrasting brown tip and its anal tube not being as long.

Description. Male. Frons as Fig. 98, with dense but very fine microtrichia. Postpedicels, with SPS vesicles (Fig. 100), palps and proboscis as Fig. 99. Thorax as Fig. 101, with 2 notopleural bristles and no cleft in front of these, and mesopleuron bare. Scutellum with an anterior pair of small hairs and a posterior pair of bristles. Abdomen as Fig. 102, the venter being pale with hairs on segments 3-6. Hypopygium as Figs 103-105, with the left hypandial lobe being bare distally and the right lobe being broad but very short. Legs very pale. Fore tarsus (Fig. 106) with posterodorsal hair palisade on segments 1-5 and 5 longer than 4 . Dorsal hair palisade of mid tibia extends about 0.72 times its length. Hairs below basal half of hind femur longer than those of anteroventral row of outer half (Fig. 107). Hind tibia with about 10 differentiated posterodorsal hairs of which only 5 are robust with the last being longest, and without anterodorsals, and a few spinules of apical combs above the longer posterior bristle being forked (Fig. 108). Wings (Fig. 109) $1.23 \mathrm{~mm}$ long. Costal index 0.53. Costal ratios $5.0: 6.3: 1$. Costal cilia (of section 3) $0.04 \mathrm{~mm}$ long. No vein 3 hair. 2 axillary bristles, the outermost being 0.05 $\mathrm{mm}$ long. Sc reaching R1. Haltere brown (Fig. 109). 


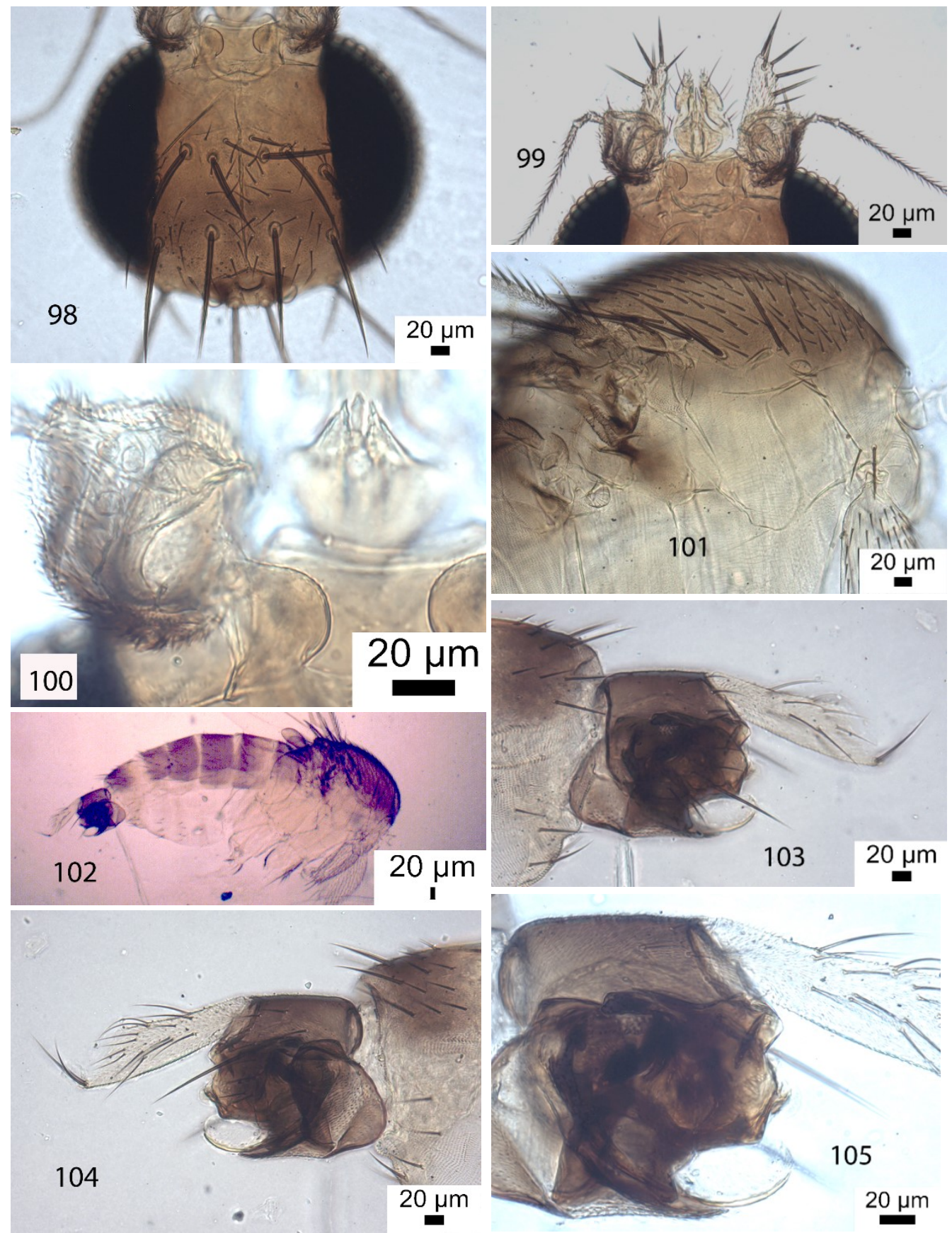

Figs 98-105. Megaselia menglaensis n. sp. male. 98 - frons; 99 - antennae, palps and proboscis; 100 - postpedicel; 101 - side of thorax; 102 - side of thorax and abdomen; 103 - left face of hypopygium; 104 - right face of hypopygium; 105 - left face of hypandrium and penis complex. 


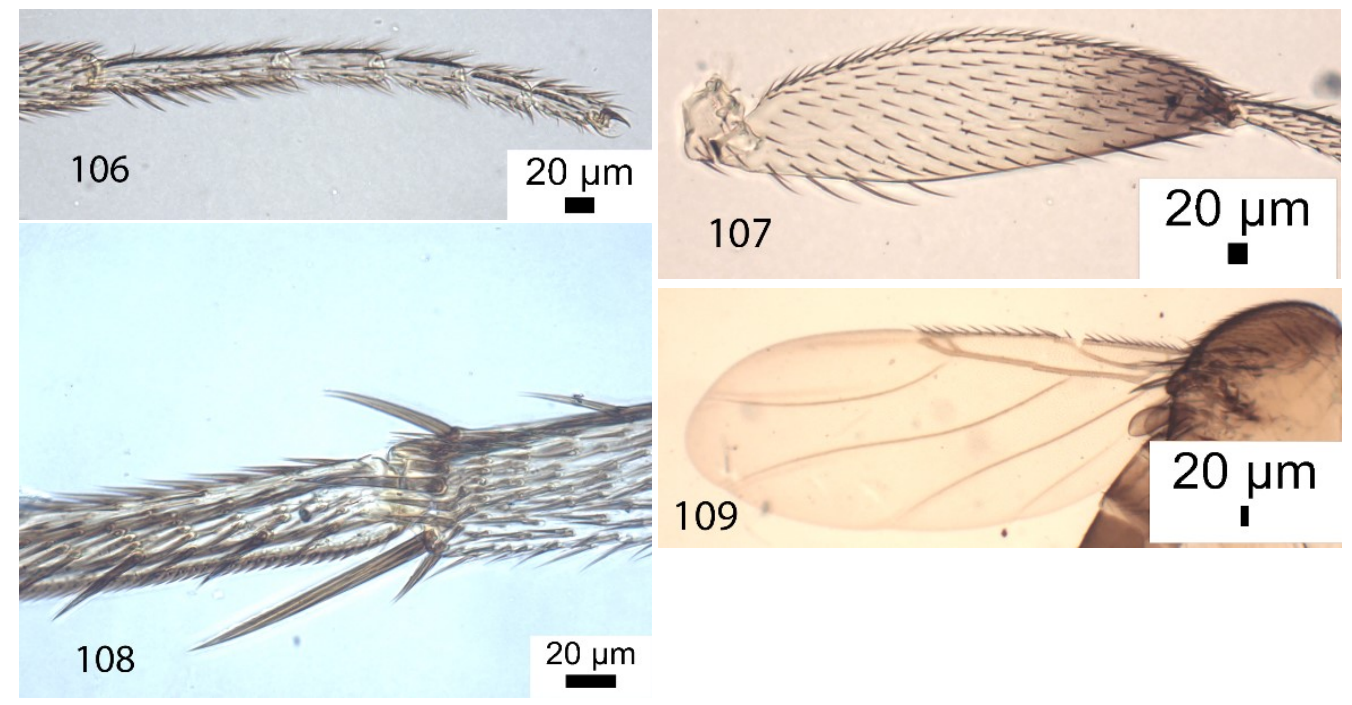

Figs 106-109. Megaselia menglaensis n. sp. male; 106 - front tarsus; 107 - hind femur; 108 - tip of hind tibia; 109 wing.

Material. Holotype male, China, Yunnan, ManNaXing Village $(10 \mathrm{~km}$ distance from Xishuangbanna Tropical Botanical Garden), Mengla, Yunnan, China, GPS: 21.875190 N, 102.277401 E, Elevation: $600 \mathrm{~m}$ a.s.1, 17 Mar 2019, at male flower of Cryptogorynae crispatula, leg. Low Shook Ling (UCMZ, 28-65).

Etymology. Named after Mengla, the region of the type locality.

\section{Megaselia shooklinglowae n. sp.}

(Figs 110-126)

Diagnosis. In the key of Borgmeier (1967b) the anterior scutellars being small bristles rather than short fine hairs means it will key out in Group VI and Group VII. In Group VI the male runs to couplet 29 lead $1 \mathrm{M}$. cuticiliata Borgmeier female. However, it has 3 axillary bristles, costal cilia 0.04-0.05 mm long and the hind femur being dusky and lacking a contrasting brown tip. 3 species running to the same point have different hypopygia, Sc running to R1, costal cilia being shorter and/or more than 2 axillary bristles. In Group VII it runs to couplets 51 and 54. At couplet 51 the hind femur being yellow with a contrasting brown tip rules out M. cuticaudata Borgmeier. Of 5 subsequently described species 2 have vein Sc running to R1. Of the remaining 3 species M. scabra Schmitz has a much shorter anal tube, $M$. kovaci Disney has the anal tube much longer than the epandrium and M. pleurota Disney has a brownish hind femur with exceptionally long hairs below its basal half, its postpedicels lack SPS vesicles and the anterior scutellars are small hairs. It fails to key out in the rest of the world fauna.

Description. Male. Frons as Fig. 110, with dense but very fine microtrichia. Cheek with 4 bristles and jowl with 2 that are longer and more robust. Postpedicels, with SPS vesicles), palps and proboscis as Fig. 111. Thorax mainly yellowish, and abdomen as Fig. 112. Thorax with 2 notopleural bristles and no cleft in front of these, and mesopleuron bare. Scutellum with an anterior pair of robust hairs $(0.085 \mathrm{~mm}$ long) and a posterior pair of bristles $(0.18 \mathrm{~mm}$ long). Abdominal venter pale with hairs on segments 3-6 (Fig. 112). Hypopygium as Figs 113-115, the left hypandrial lobe being well developed and with projecting microtrichia (Fig. 113). The right lobe is vestigial. Legs yellow apart from brown tip to hind femur (Fig. 117). Fore tarsus 
(Fig. 116) with posterodorsal hair palisade on segments 1-5 and 5 longer than 4 . Dorsal hair palisade of mid tibia extends about 0.73 times its length. Hairs below basal half of hind femur longer than those of anteroventral row of outer half (Fig. 117). Hind tibia with about a dozen differentiated posterodorsal hairs, without anterodorsals, and spinules of apical combs simple. Wings (Fig. 118) $1.48 \mathrm{~mm}$ long. Costal index 0.45. Costal ratios $3.6: 2.3: 1$. Costal cilia (of section 3) $0.09 \mathrm{~mm}$ long. Vein 3 hair $0.04 \mathrm{~mm}$ long. 2 axillary bristles, the outermost being 0.08 $\mathrm{mm}$ long. Sc not reaching R1. Haltere knob pale.
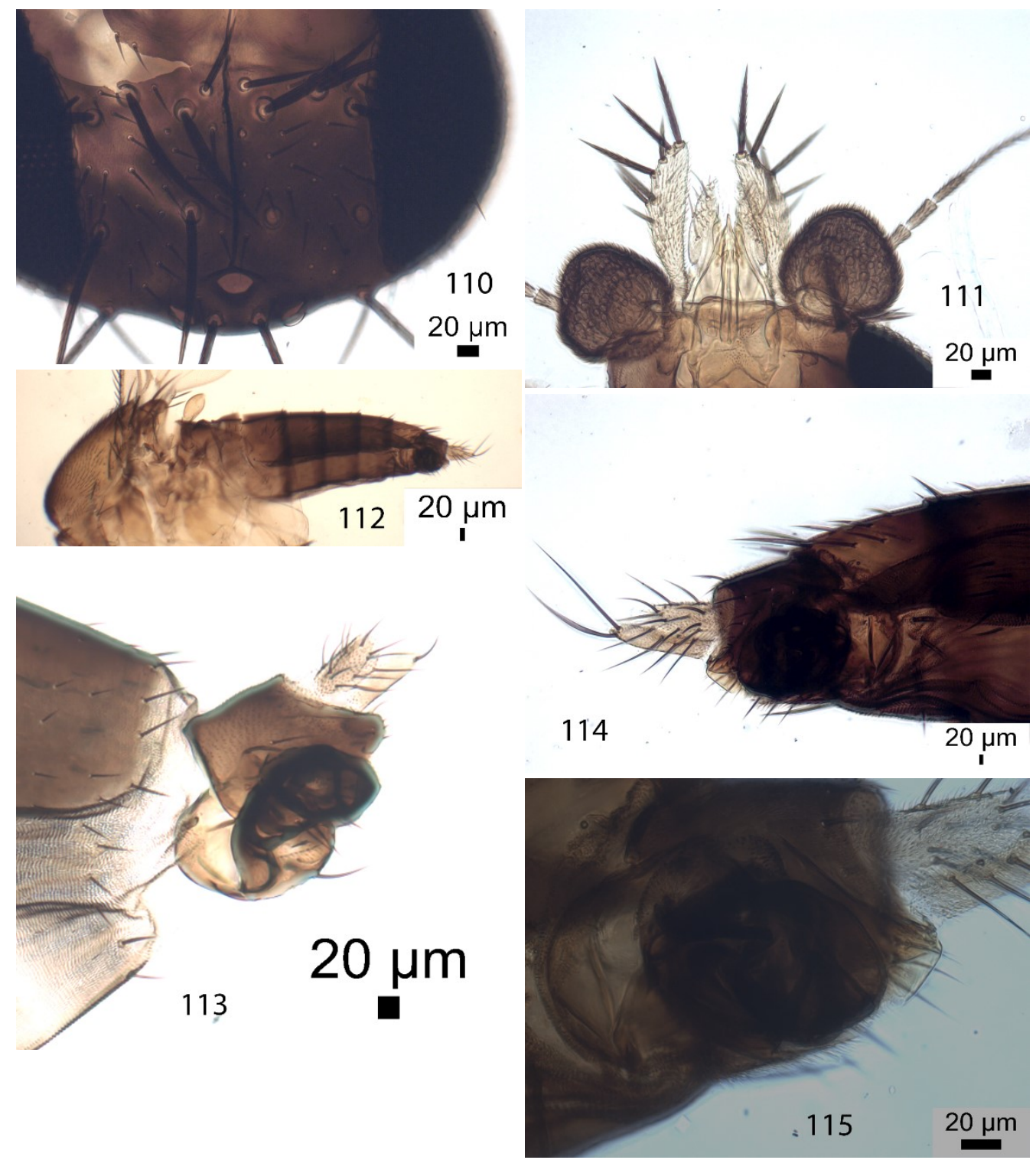

Figs 110-115. Megaselia shooklinglowae n. sp. male. 110 - frons; 111 - antennae, palps and proboscis; 112 - abdomen; 113 - left face of hypopygium; 114 - right face of hypopygium; 115 - left face of hypandrium. 

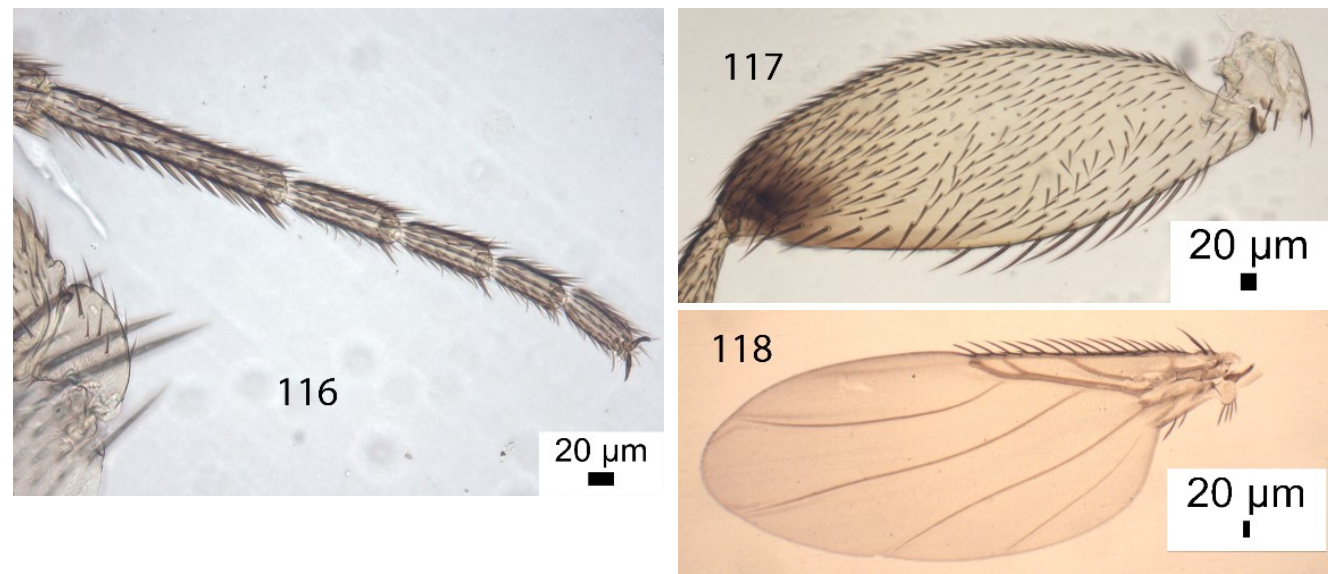

Figs 116-118. Megaselia shooklinglowae n. sp. male; 116 - front tarsus; 117 - hind femur; 118 - wing.

Female. Frons as Fig. 119. Postpedicels, with SPS vesicles, palps and proboscis similar to male (Fig. 111). Side of thorax as Fig. 120. Abdominal tergites as Fig. 121. Tergite 7 as Fig. 122. Sternite 7 to tip of abdomen as Fig. 123. Dufour's crop mechanism as Fig. 124. Furca as Fig. 125. Wing (Fig. 126) $1.82 \mathrm{~mm}$ long and costal index 0.46. Costal ratios $3.5: 2.0: 1$. Costal cilia $0.11 \mathrm{~mm}$ long. Vein $30.05 \mathrm{~mm}$ long. Outer axillary bristle $0.10 \mathrm{~mm}$ long. Otherwise it and haltere as male.
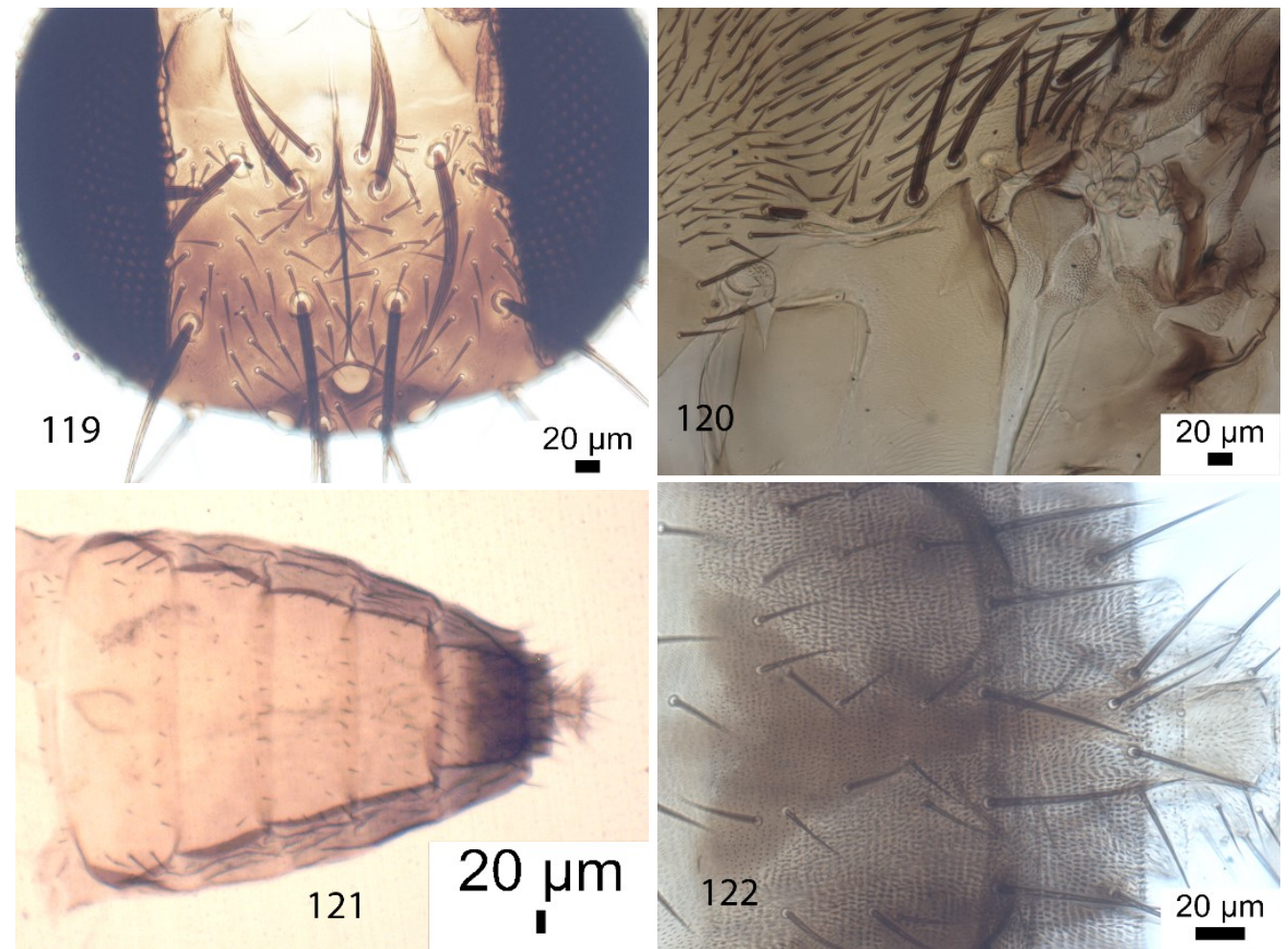

Figs 119-122. Megaselia shooklinglowae n. sp. female. 119 - frons; 120 - side of thorax; 121 - abdomen; 122 - tergite 8. 


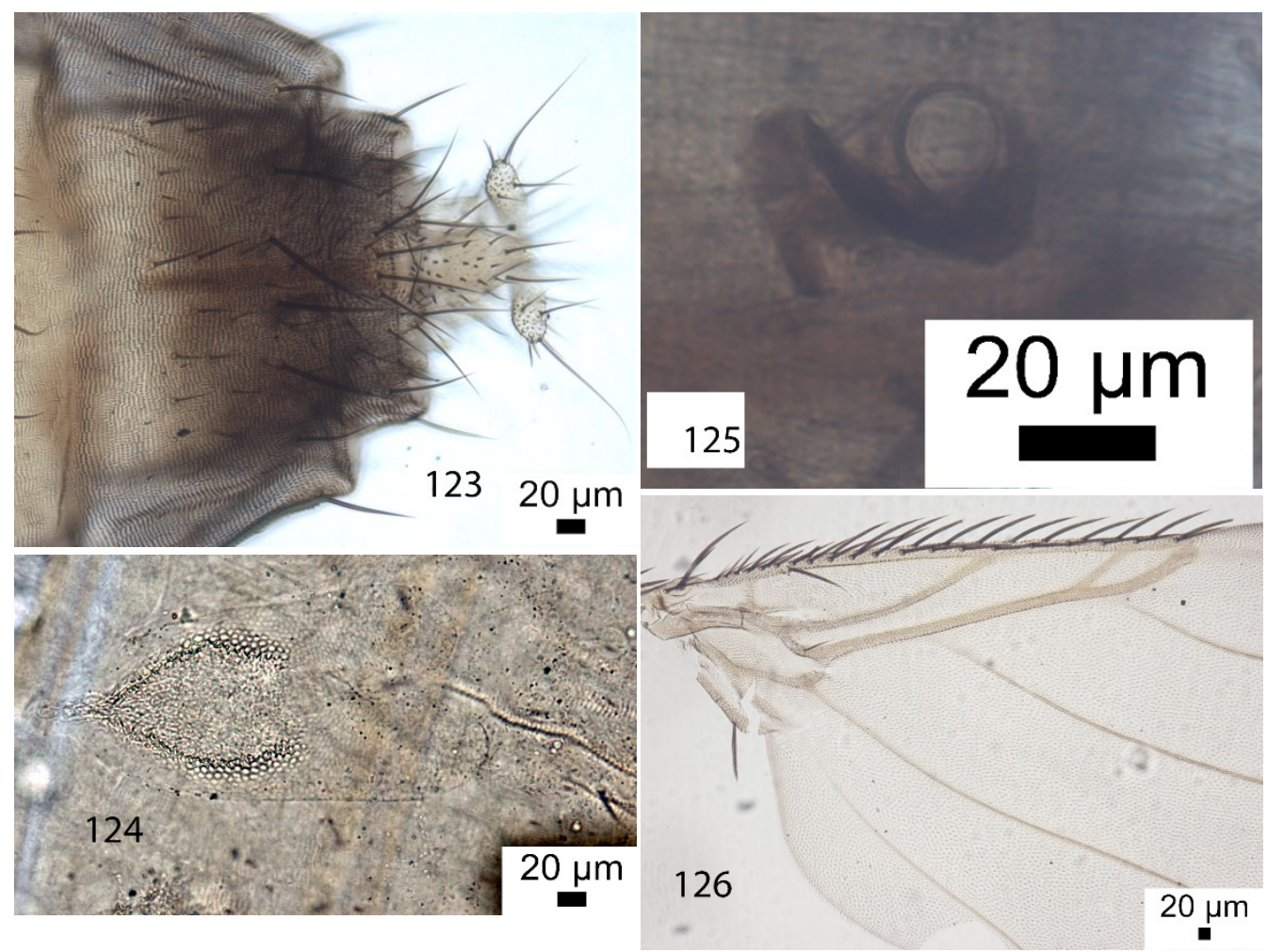

Figs 123-126. Megaselia shooklinglowae n. sp. female; 123 - sternite 7 to tip of abdomen; 124 - Dufour's crop mechanism; 125 - furca; 126 - wing base.

Material. Holotype male, China, Yunnan, ManNaXing Village $(10 \mathrm{~km}$ distance from Xishuangbanna Tropical Botanical Garden), Mengla, Yunnan, China.

GPS: 21.859876 N, 101.272633 E, Elevation: $600 \mathrm{~m}$ a.s.l., at female flower, 30 Mar 2019 (UCMZ, 28-79). Paratype female as holotype except 22 Mar 2019 (UCMZ, 28-76)

Etymology. Named after Low Shook Ling, the collector of all the specimens described in this paper.

\section{Megaselia species Y1, female}

(Figs 127-138)

Diagnosis. In Borgmeier's (1967a) key to Group IV it runs to couplet 8, where neither option fits. This very distinctive female cannot be named until associated with its male. The very short but wide abdominal tergite 3 with its concave hind margin plus the pair of long, finger like processes at the rear of the sides of segment 6 of the abdominal venter excludes most species in the giant genus Megaselia. The most similar species is M. tubularia Disney (2016) from the Russian Far East. Its female is immediately distinguished from all other known Megaselia females by the embayment of costal section I of its wings. In Schmitz \& Beyer's (1965) key to the Palaearctic species of Abteilung IV, Zweite Reihe its male runs to couplet 62. Allowing for sexual dimorophism, the male of the female described below would run to couplets 62 to 76 . The combination of the female's costal index of 0.6 , its short costal cilia $(0.07 \mathrm{~mm}$ long) and subcosta running to vein 1 rules out most of the males in these couplets. The females of the rest are known and are essentially typical of the genus. 


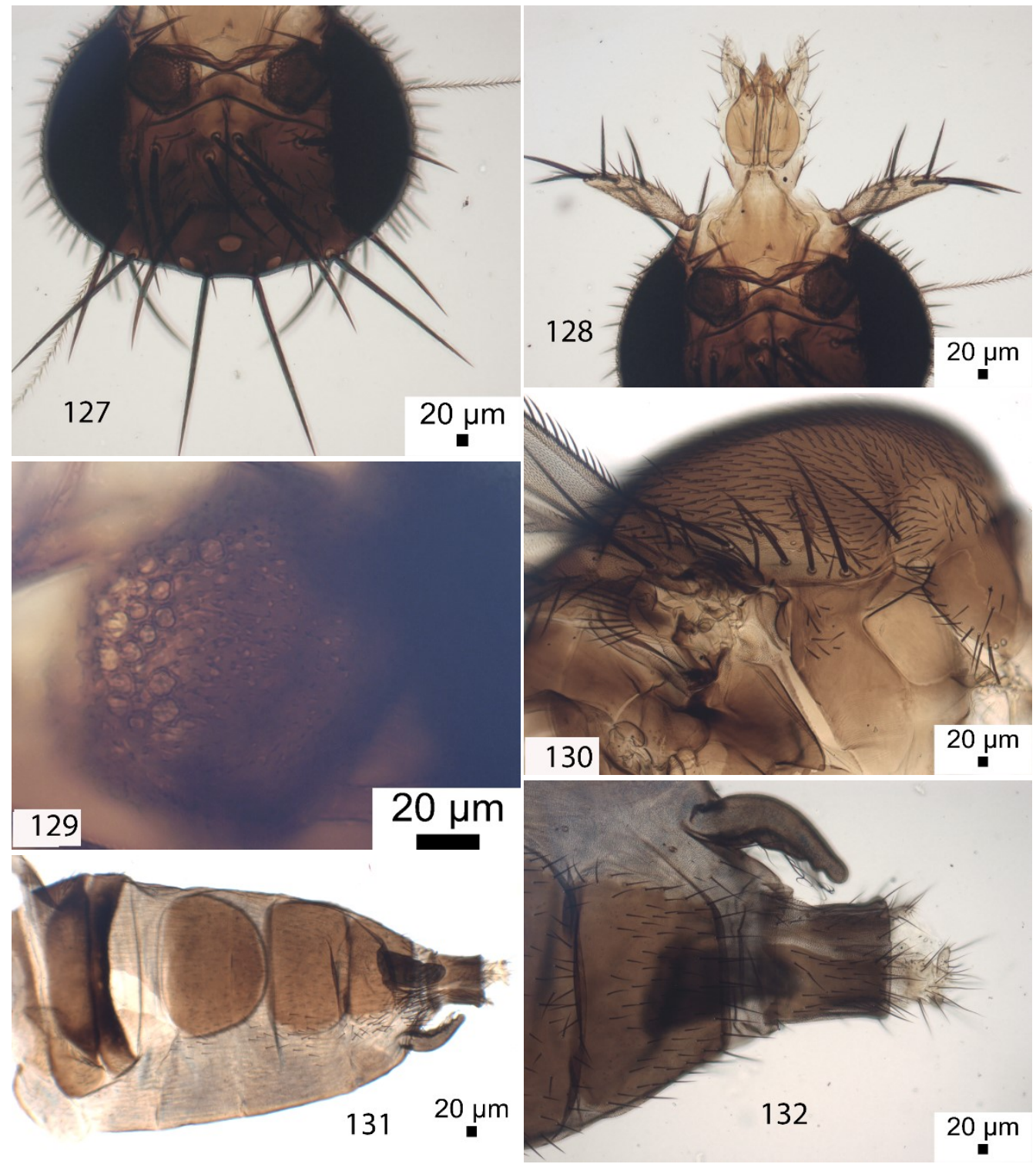

Figs 127-132. Megaselia species Y1. female. 127 - frons; 128 - antennae, palps and proboscis; 129 - postpedicel; 130 - side of thorax; 131 - abdomen; 132 - tergite 6 to tip of abdomen.

Description. Female. Frons as Fig. 127, with dense but very fine microtrichia. Cheek with 5 bristles and jowl with 2 that are much longer and more robust. Postpedicels, with SPS with SPS vesicles (Fig. 129), palps and proboscis as Fig. 128; Side of thorax as Fig. 130, having 3 notopleural bristles and no cleft in front of these, and mesopleuron with hairs. Scutellum with an anterior pair of robust hairs $0.13 \mathrm{~mm}$ long and a posterior pair of bristles $0.26 \mathrm{~mm}$ long. Abdomen as Fig. 131. Tergite 6 to tip of abdomen as Fig. 132. Sternite 6 to tip of abdomen as Fig. 133. Sternite 7 and sternum 8 as Fig. 134. Dufour's crop mechanism as Fig. 135. Legs yellow. Fore tarsus with posterodorsal hair palisade on segments $1-5$ and 5 longer than 4 (Fig. 136). Dorsal 
hair palisade of mid tibia extends about 0.6-0.7 times its length. Hairs below basal half of hind femur longer than those of anteroventral row of outer half (Fig. 137). Hind tibia with about 20 differentiated posterodorsal hairs, without anterodorsals, and spinules of apical combs simple. Wings (Fig. 138) $2.60 \mathrm{~mm}$ long. Costal index 0.60. Costal ratios $3.0: 2.3: 1$. Costal cilia (of section 3) $0.07 \mathrm{~mm}$ long. Vein 3 with 2 hairs $0.02 \mathrm{~mm}$ long. 5 axillary bristles, the outermost being $0.14 \mathrm{~mm}$ long. Sc reaching R1. Haltere pale.

Material. Female, China, ManNaXing Village $(10 \mathrm{~km}$ distance from Xishuangbanna Tropical Botanical Garden), Mengla, Yunnan.

GPS: 21.859876 N, 101.272633 E, Elevation: 600 m a.s.l. 24 Mar 2019, leg. Low Shook Ling (UCMZ, 28-78).

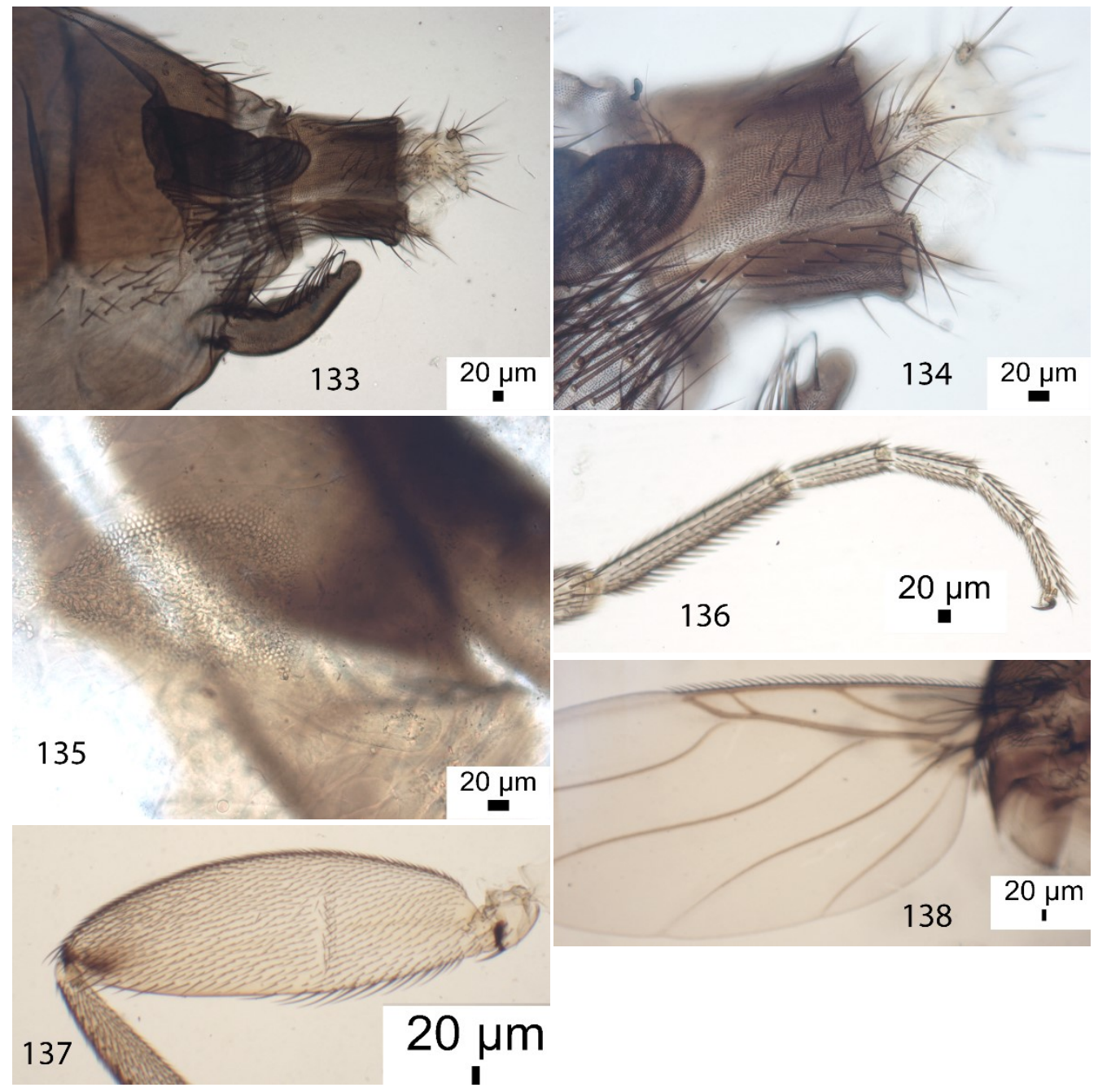

Figs 133-138. Megaselia species Y1. female; 133 - sternum 6 to tip of abdomen; 134 - sternite 7 and sternum $8 ; 135$ Dufour's crop mechanism; 136 - front tarsus; 137 - hind femur; 138, - wing. 


\section{Puliciphora Dahl}

The recognition of the species in this large genus is based on the flightless females and males are currently only named when associated with their females. Those known from females or both sexes are covered by Disney (1999a, 2005a) and Maruyama \& Disney (2008). Liu (2001) described four males (species A-D) and referred to the male of P. fungicola Yang \& Wang (1993) described from both sexes. He also collected both sexes of. P. obtecta de Meijere (1912) in Guandong. The males are primarily distinguished by the details of their hypopygia. The following males were obtained in this study.

\section{Puliciphora species Y1, male}

(Figs 139-140)

Description. Hypopygium (Figs 139-140) with hairs of epandrium about as long as those at rea of tergite 6 . Dorsal edge of epandrium shorter than ventral edge on left side and posterior edge sloping rearwards. Anal tube longer than epandrium.

Material. Male, China, Yunnan, ManNaXing Village (10 km distance from Xishuangbanna Tropical Botanical Garden), Mengla, Yunnan, China.

GPS: 21.859876 N, 101.272633 E, Elevation: 600 m a.s.1., at female flower, 30 Mar 2019 (UCMZ, 28-73).

\section{Puliciphora species Y2, male}

(Figs 141-142)

Description. Hypopygium (Figs 141-142) with long bristles on epandrium and finger like surstyli.

Material. 2 males, China, Yunnan, ManNaXing Village $(10 \mathrm{~km}$ distance from Xishuangbanna Tropical Botanical Garden), Mengla, Yunnan, China.

GPS: 21.859876 N, 101.272633 E, Elevation: $600 \mathrm{~m}$ a.s.l., at female flower, 30 Mar 2019 (UCMZ, 28-71 \& 79).

\section{Puliciphora species Y3, male}

(Figs 143-144)

Description. Hypopygium (Figs 143-144) with hairs of epandrium about as long as those at rear of tergite 6 . Dorsal edge of epandrium convex and rear edge nearly vertical. Anal tube longer than epandrium.

Material. Male, China, Yunnan, ManNaXing Village (10 km distance from Xishuangbanna Tropical Botanical Garden), Mengla, GPS: 21.875190 N, 102.277401 E, Elevation: 600 m a.s.l, 16 Mar 2019, at male flower of Cryptogorynae crispatula, leg. Low Shook Ling (UCMZ, 2869).

\section{Puliciphora species Y4, male}

(Figs 145-146)

Description. Hypopygium (Figs 145-146) with anal tube shorter than epandrium.

Material. Male, China, Yunnan, ManNaXing Village (10 km distance from Xishuangbanna Tropical Botanical Garden), Mengla, GPS: 21.875190 N, 102.277401 E, Elevation: 600 m a.s.l, 16 Mar 2019, at male flower of Cryptogorynae crispatula, leg. Low Shook Ling (UCMZ, 2866). 

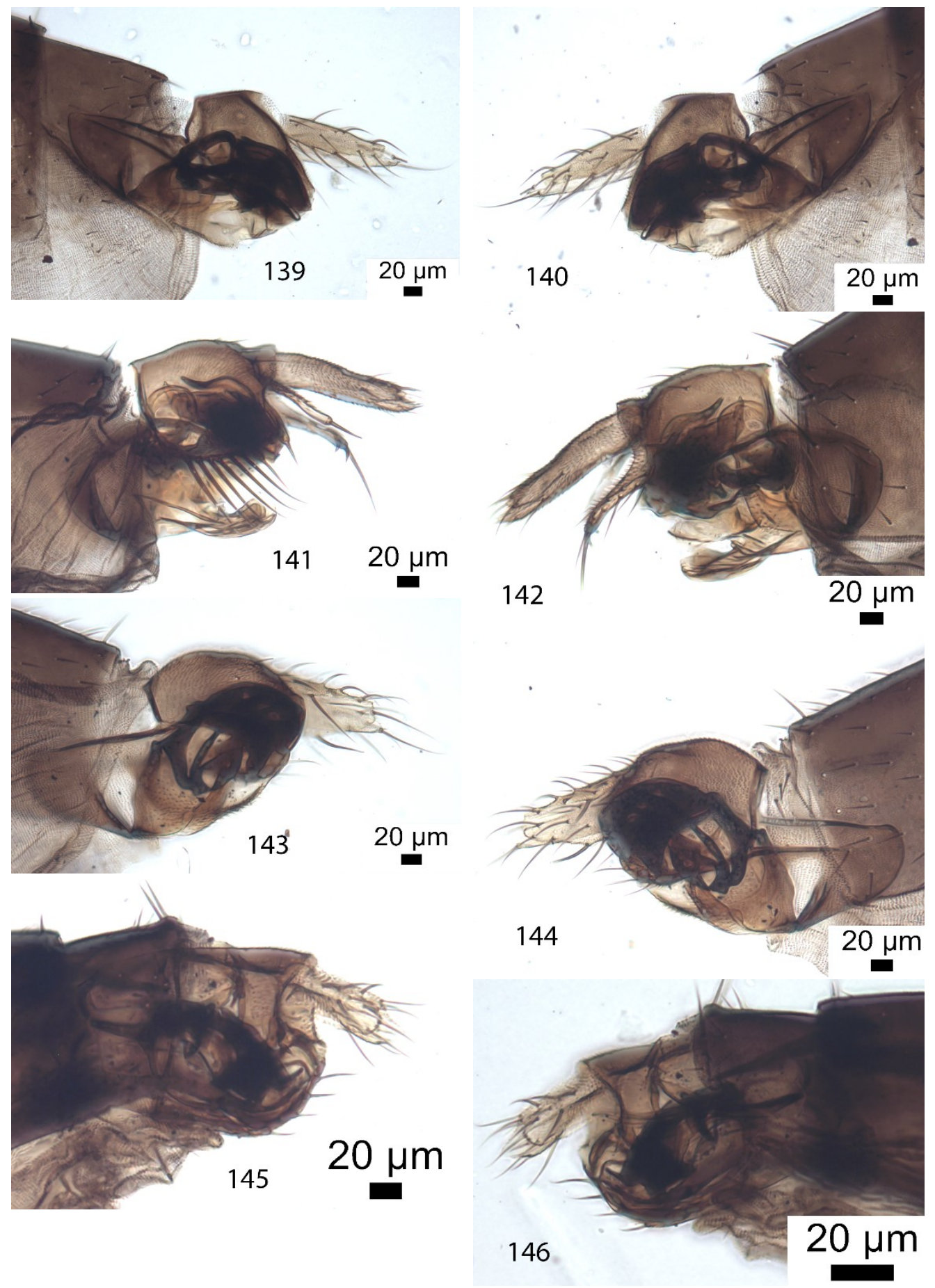

Figs 139-146. Puliciphora species Y1-Y4, males, left and right views of hypopygia. 139-140 - speciesY1; 141-142 speciesY2; 143-144-speciesY3; 145-146- speciesY4. 


\section{Puliciphora species Y5, male}

(Figs147-148)

Description. Hypopygium (Figs147-148) with epandrium height about twice its breadth and anal tube longer than epandrium.

Material. Male, China, Yunnan, ManNaXing Village (10 km distance from Xishuangbanna Tropical Botanical Garden), Mengla, Yunnan, China.

GPS: 21.859876 N, 101.272633 E, Elevation: $600 \mathrm{~m}$ a.s.1., at female flower, 30 Mar 2019 (UCMZ, 28-73).

\section{Puliciphora species Y6, male}

(Figs 149-150)

Description. Hypopygium (Figs 149-150) with epandrium height more than its length and long bristles at rear of tergite 6.

Material. Male, China, Yunnan, ManNaXing Village (10 km distance from Xishuangbanna Tropical Botanical Garden), Mengla, GPS: 21.875190 N, 102.277401 E, Elevation: 600 m a.s.1, 16 Mar 2019, at male flower of Cryptogorynae crispatula, leg. Low Shook Ling (UCMZ, 28$65)$.
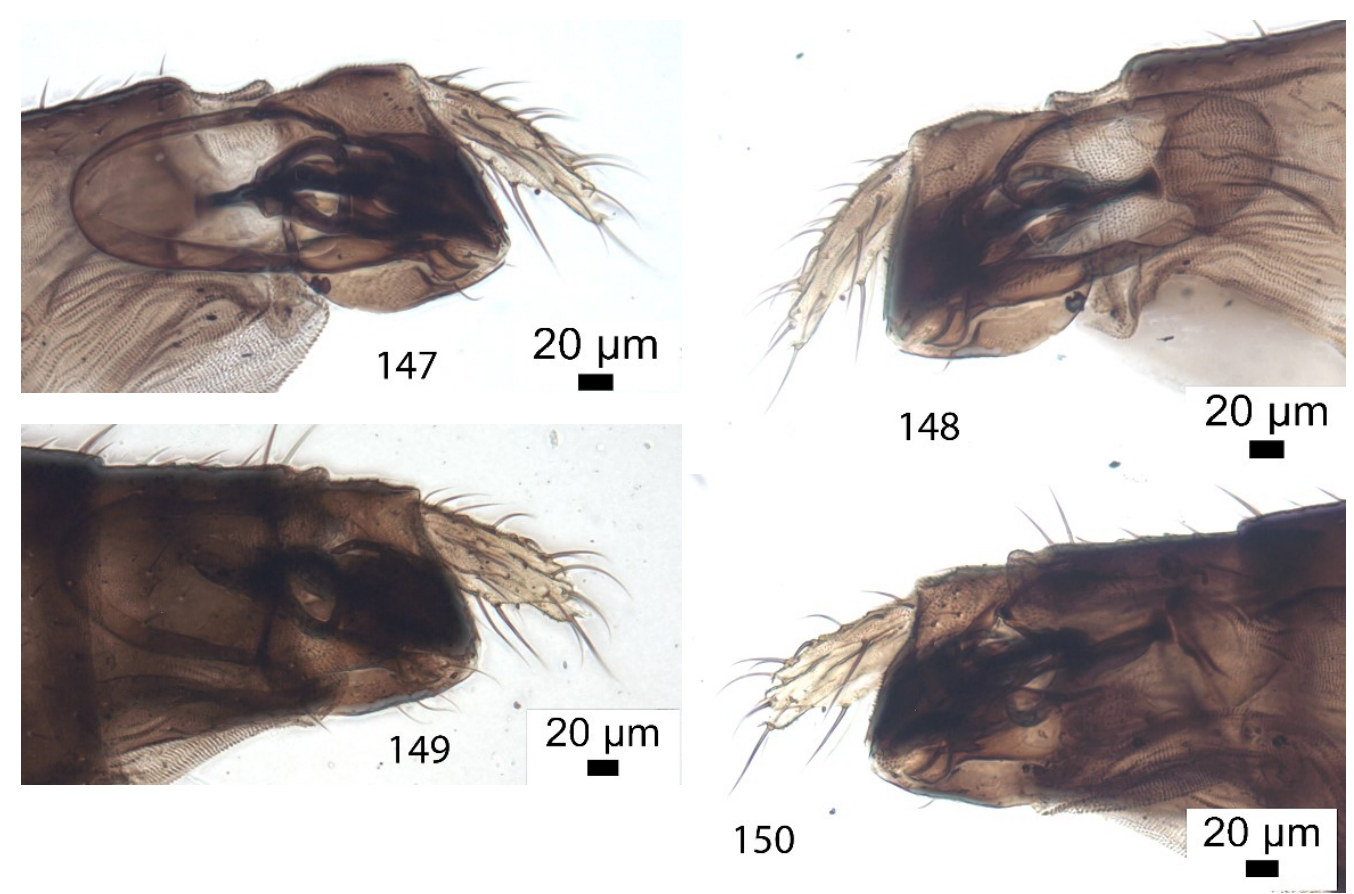

Figs 147-150. Puliciphora species Y5-Y6, males, left and right views of hypopygia; 147-148 - species Y5; $149-150$ speciesY6. 


\section{Woodiphora Schmitz}

More than fifty species are known in this cosmopolitan genus. Females can only be named when associated with their males. The Australasian and Oriental species are keyed by Disney (1989), supplemented by Disney (1997, 2005a), Bänziger \& Disney (2006), Zhu \& Liu (2009), Disney \& Bänziger (2009), Zuha \& Disney (2017). Liu (2001) covers the then known Chinese species. In the present study only $W$. parvula Schmitz, 1927 was identified. The following species require their associated males in order to be named. They all differ from many of the known species in lacking both of the following features that characterize species that have vein 3 not forked (i.e. vein $2+3$ absent) and/or the hind tibia having a dorsal hair palisade.

\section{Woodiphora species A, female}

(Figs 151-157)

Description. Frons as Fig. 151. Antennae, palps and proboscis as Fig. 152. abdominal tergites 1-4 as Fig. 153; tergites 5 and 6 and furca as Fig. 154; tergite 7 to tip of abdomen plus furca as Fig. 155; hind femur and tibia as Fig. 156; wing as Fig. 157.

Material. Female, China, Yunnan, ManNaXing Village $(10 \mathrm{~km}$ distance from Xishuangbanna Tropical Botanical Garden), Mengla, GPS: 21.859876 N, 101.272633 E, Elevation: 600 m a.s.1, 16 Mar 2019, at male flower of Cryptogorynae crispatula, leg. Low Shook Ling (UCMZ, 28-69).
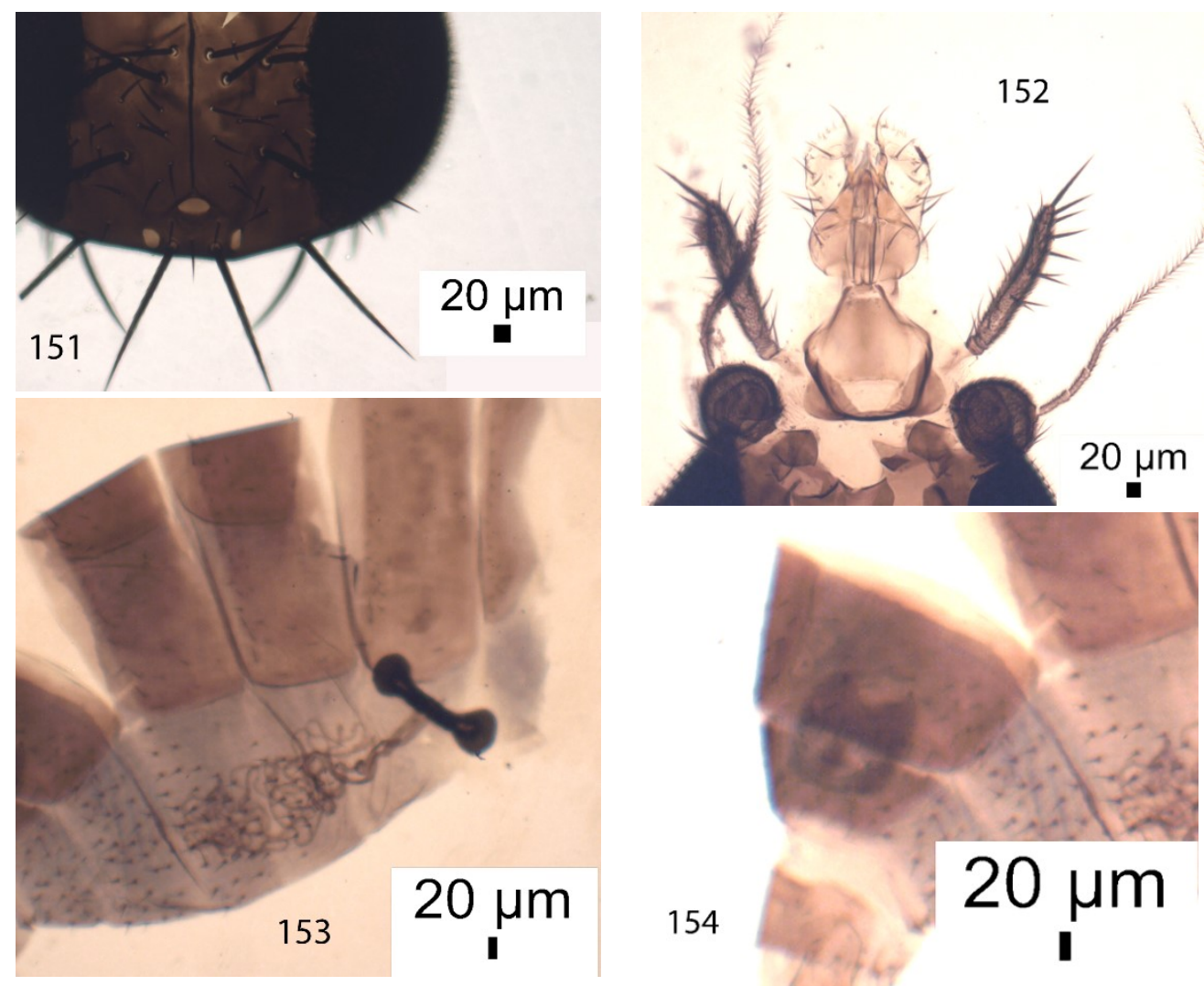

Figs 151-154. Woodiphora species A, female. 151 - frons; 152 - antennae, palps and proboscis; 153 - abdominal tergites $1-4 ; 154$ - tergites 5-7. 

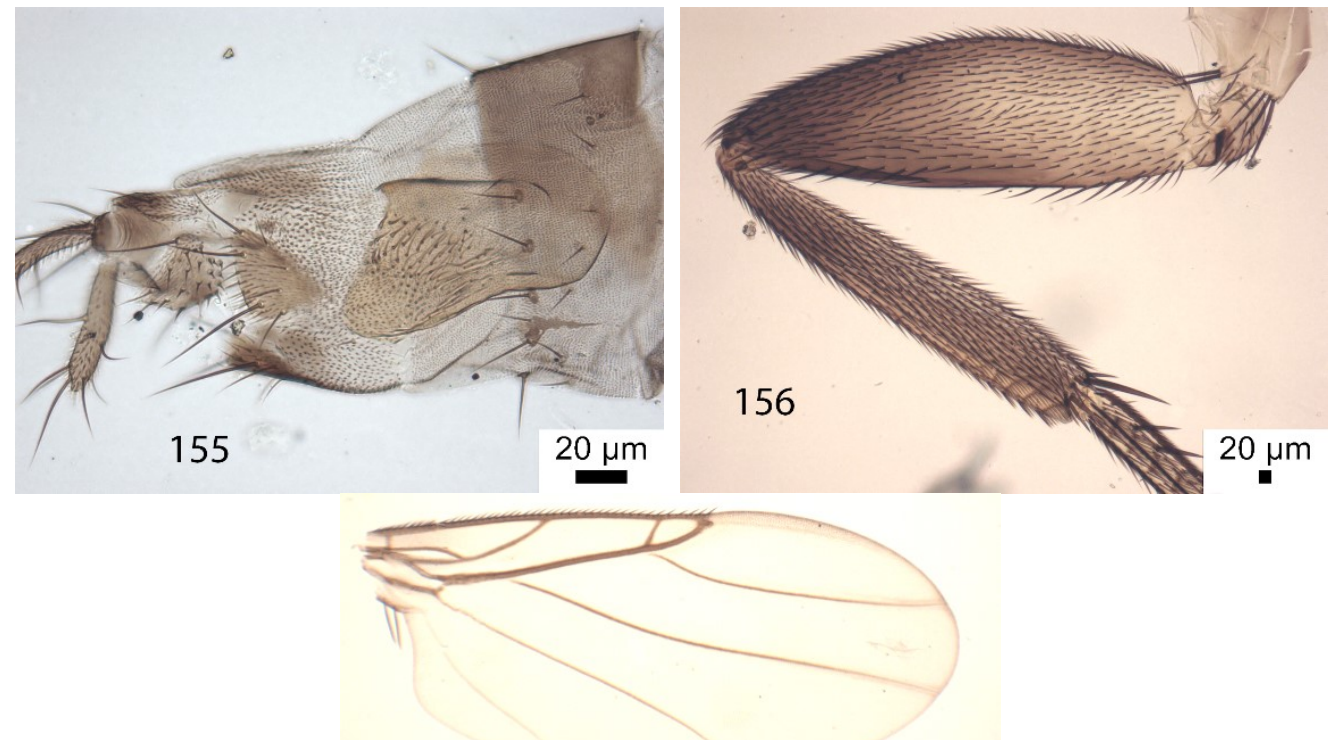

157

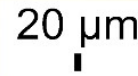

Figs 155-157. Woodiphora species A, female; 155 - tergite 7 to tip of abdomen plus furca; 156 - hind femur and tibia; 157 - wing.

Woodiphora species B, female

(Figs 158-165)

Description. Frons as Fig. 158. Antennae and palps as Fig. 159; proboscis as Fig. 160; abdomen as Figs 161-162; furca as Fig. 163; hind femur as Fig. 164; wing as Fig. 165.

Material. Female, China, Yunnan, ManNaXing Village $(10 \mathrm{~km}$ distance from Xishuangbanna Tropical Botanical Garden), Mengla, GPS: 21.875190 N, 102.277401 E, Elevation: 600 m a.s.1, 17 Mar 2019, at male flower of Cryptogorynae crispatula, leg. Low Shook Ling (UCMZ, 28-65).
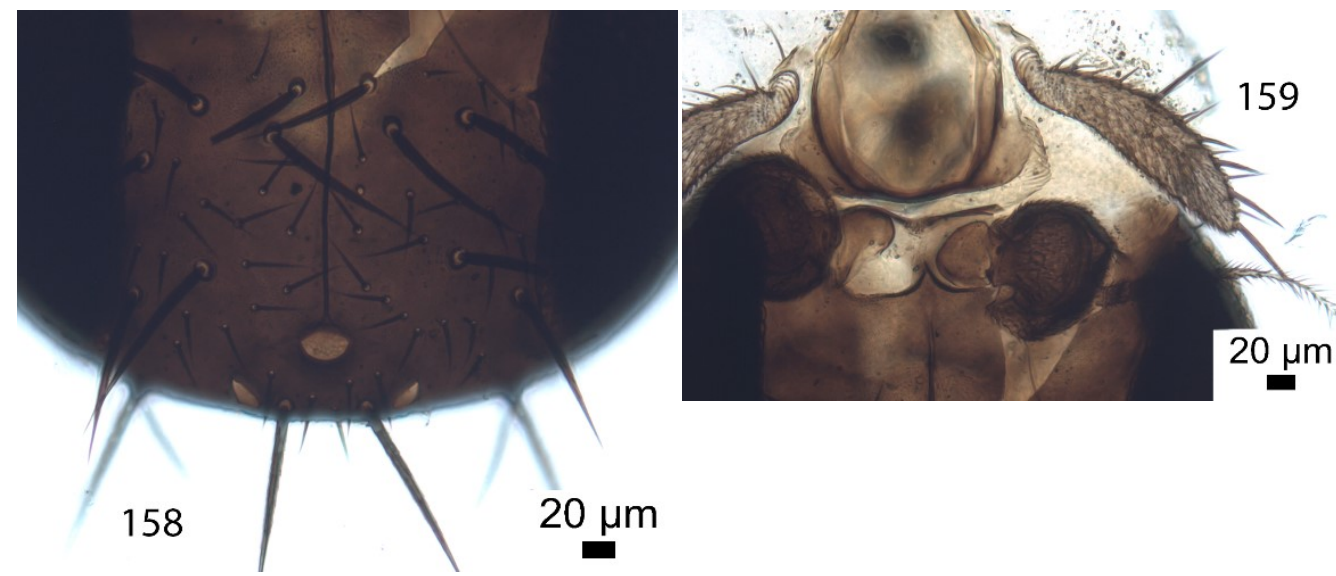

Figs 158-159. Woodiphora species B, female. 158 - frons; 159 - antennae and palps. 


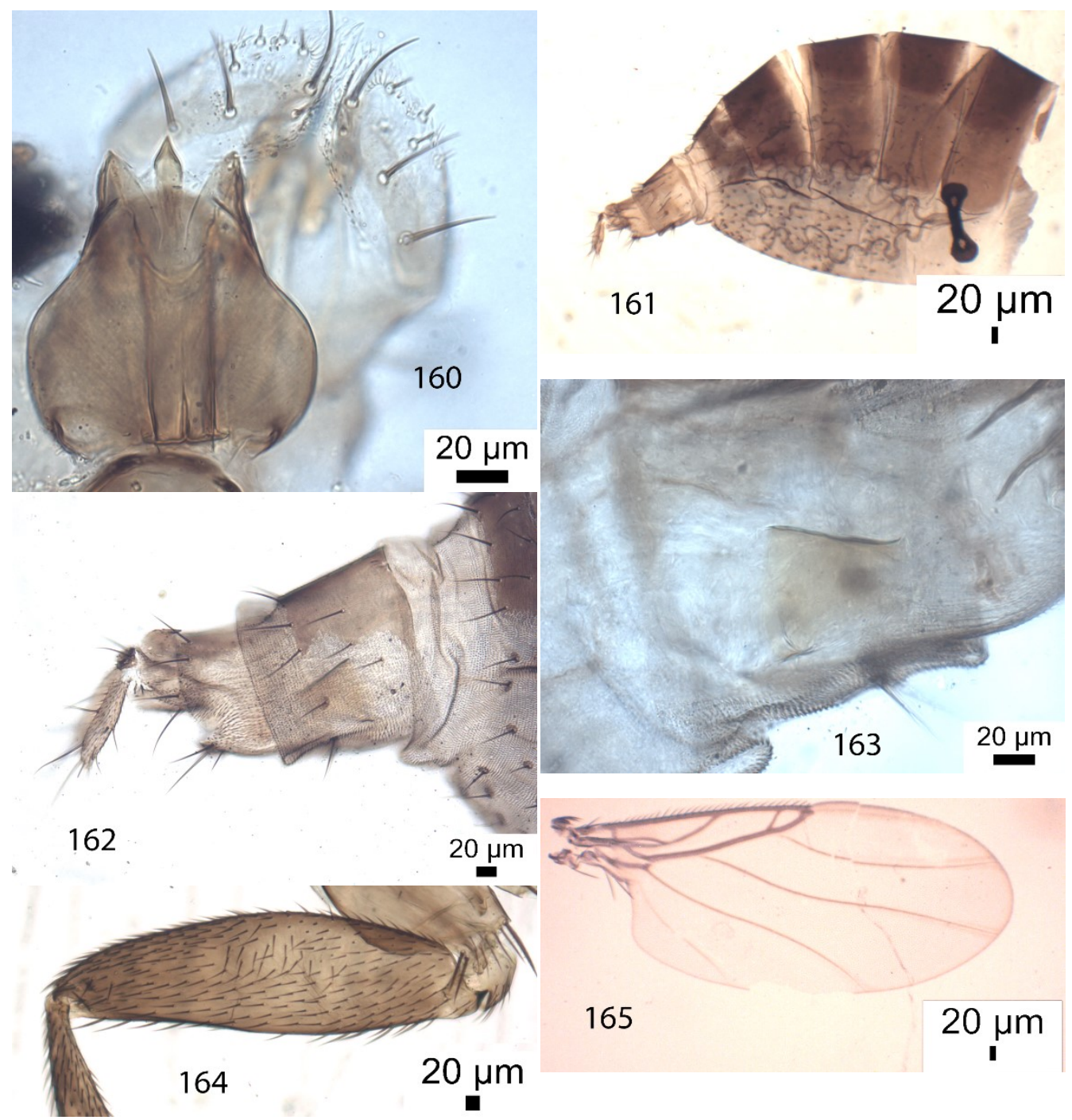

Figs 160-165. Woodiphora species B, female; 160 - proboscis; 161-162 - Abdomen; 163 - furca; 164 - hind femur; 165 - wing.

Woodiphora species C, female

(Figs 166-173)

Description. Frons as Fig. 166; postpedicel as Fig. 167; palp as Fig. 168; abdomen as Fig. 169; tergite 7 as Fig. 170; furca as Fig. 171; hind femur, tibia and basitarsus as Fig. 172; wing as Fig. 173, with the thin veins very pale.

Material. Female, China, Yunnan, ManNaXing Village $(10 \mathrm{~km}$ distance from Xishuangbanna Tropical Botanical Garden), Mengla, GPS: 21.875190 N, 102.277401 E, Elevation: 600 m a.s.1, 17 Mar 2019, at male flower of Cryptogorynae crispatula, leg. Low Shook Ling (UCMZ, 28-65). 


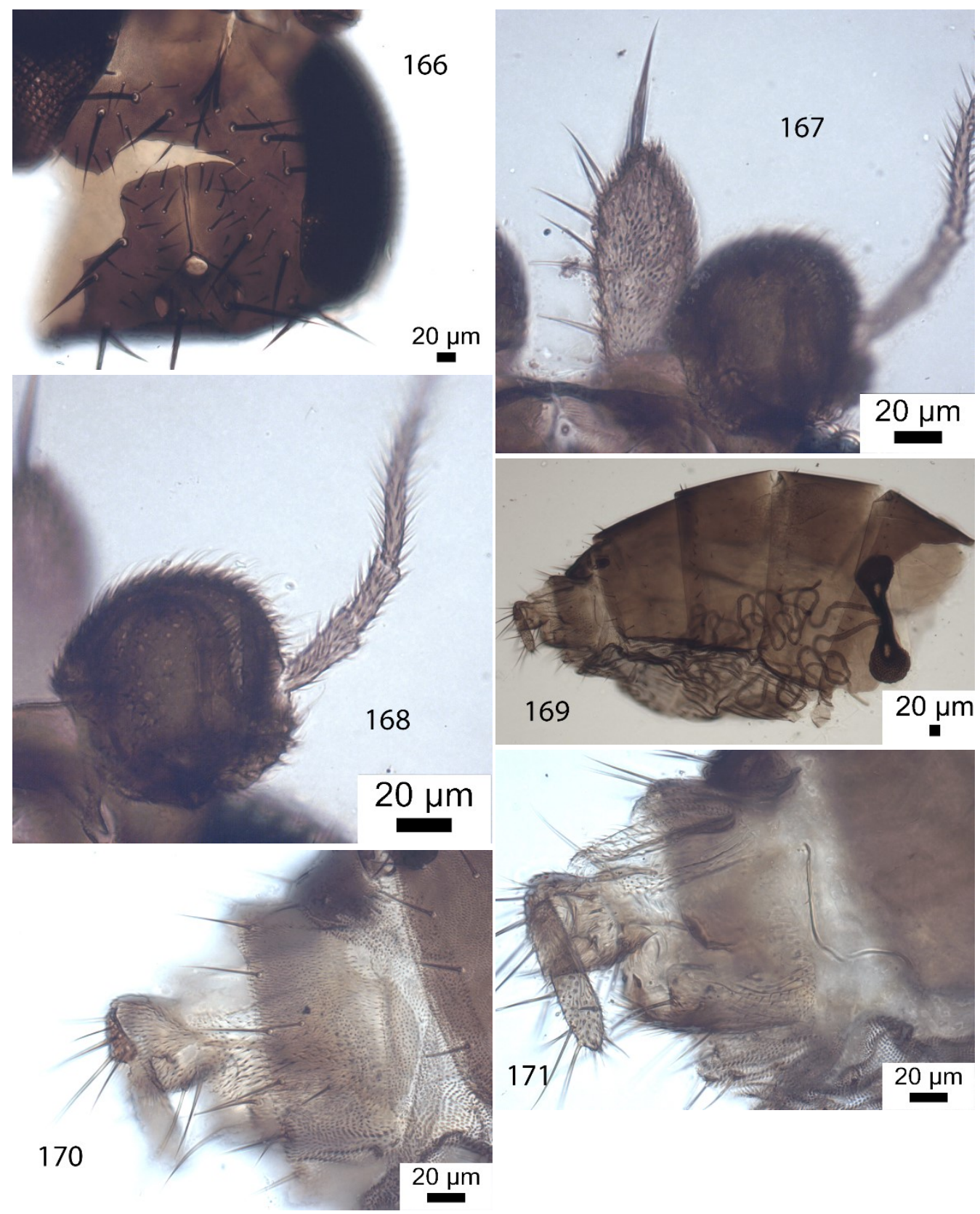

Figs 166-171. Woodiphora species C, female; 166 - frons; 167 - posspedicel and palp; 168 - postpedicel; 169 abdomen; 170 - tergite 7; 171 - furca. 


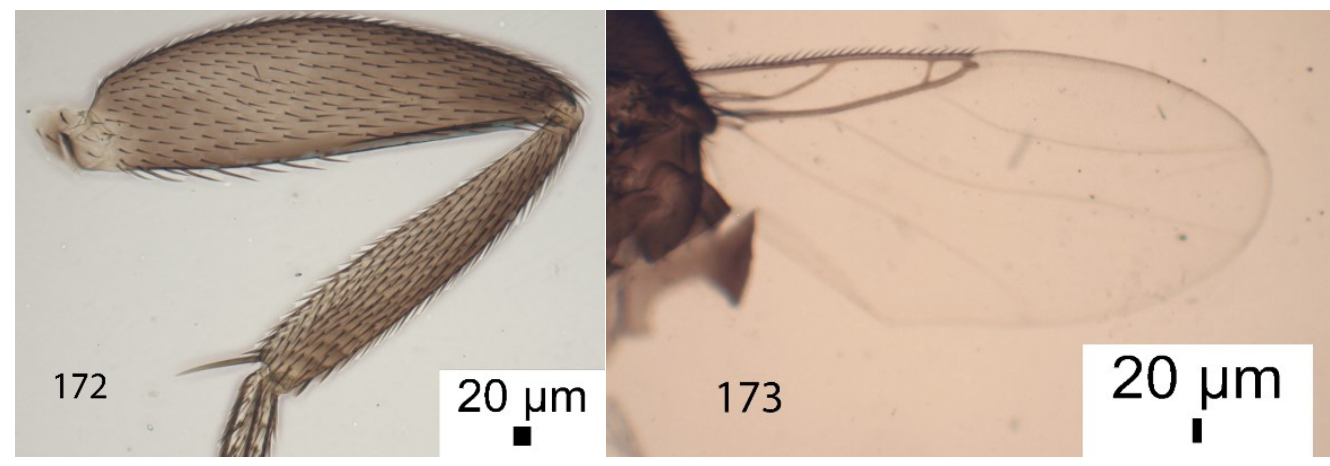

Figs 172-173. Woodiphora species C, female; 172 - hind femur, tibia and basitarsus; 173 - wing.

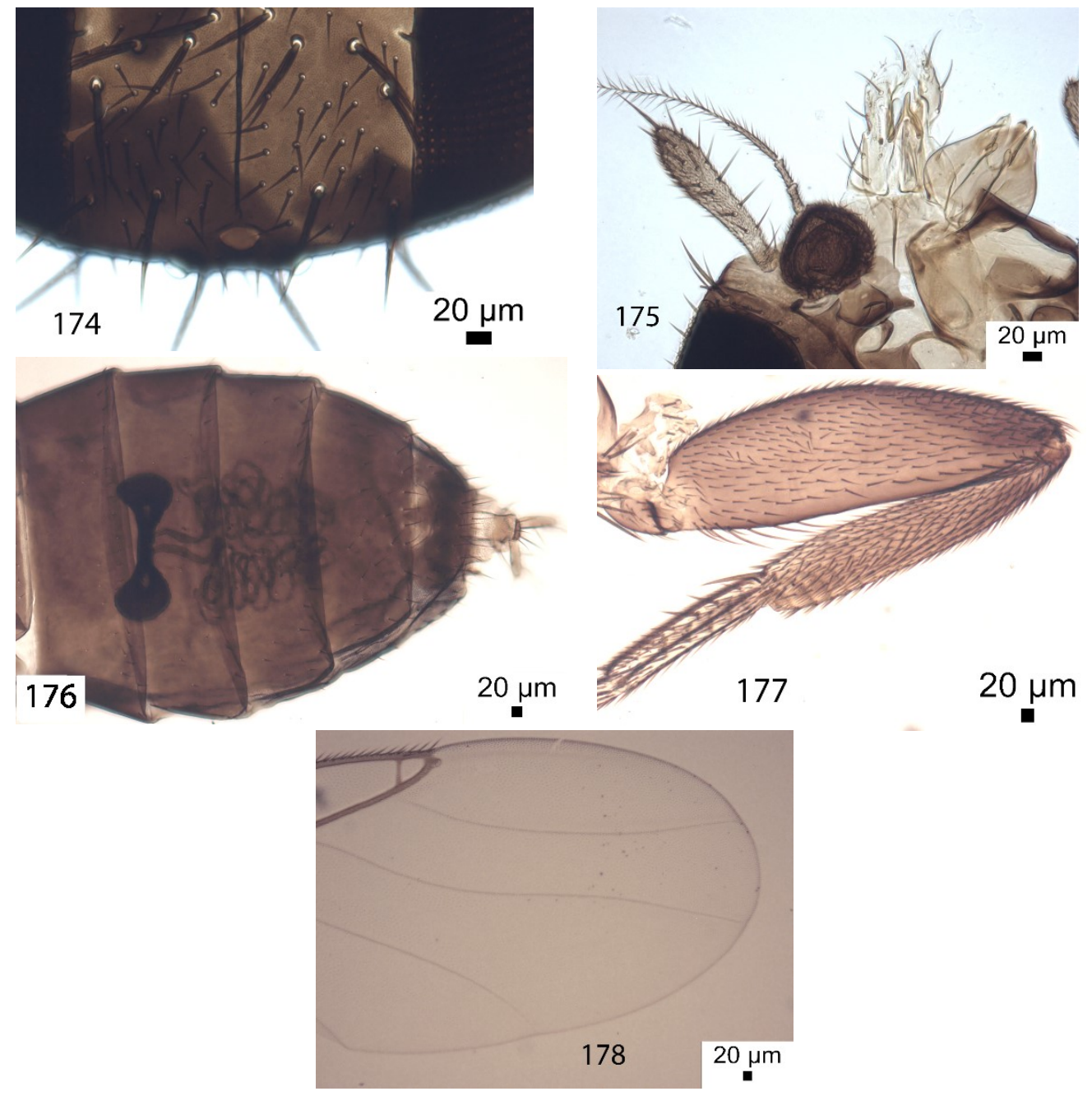

Figs 174-178. Woodiphora species D, female. 174 - frons; 175 - antenna, palp and proboscis; 176 - abdomen; 177 hind femur; 178 - wing 


\section{Woodiphora species D, female}

(Figs 174-178)

Description. Frons as Fig. 174; antennae and palps as Fig. 175; abdomen as Fig. 176; hind femur as Fig. 177; wing as Fig. 178, with pale thin veins and vein $2+3$ running directly forwards to the costa.

Material. Female, China, Yunnan, ManNaXing Village $(10 \mathrm{~km}$ distance from Xishuangbanna Tropical Botanical Garden), Mengla, GPS: 21.859876 N, 101.272633 E, Elevation: 600 m a.s.1, 17 Mar 2019, at male flower of Cryptogorynae crispatula, leg. Low Shook Ling (UCMZ, 28-67).

\section{Woodiphora species E, female}

(Figs 179-185)

Description. Frons as Fig. 179; antennae and palps as Fig. 180; abdomen as Fig, 181; sternite 7 and sternum 8 as Fig. 182; furca as Fig. 183; hind femur as Fig. 184; wing as Fig. 185.

Material. Five females, China, Yunnan, ManNaXing Village $(10 \mathrm{~km}$ distance from Xishuangbanna Tropical Botanical Garden), Mengla, GPS: 21.875190 N, 102.277401 E, and GPS: 21.859876 N, 101.272633 E, Elevation: $600 \mathrm{~m}$ a.s.1, 16, 22, 24 Mar 2019, at male flower of Cryptogorynae crispatula, leg. Low Shook Ling (UCMZ, 28-70, 77, 78).

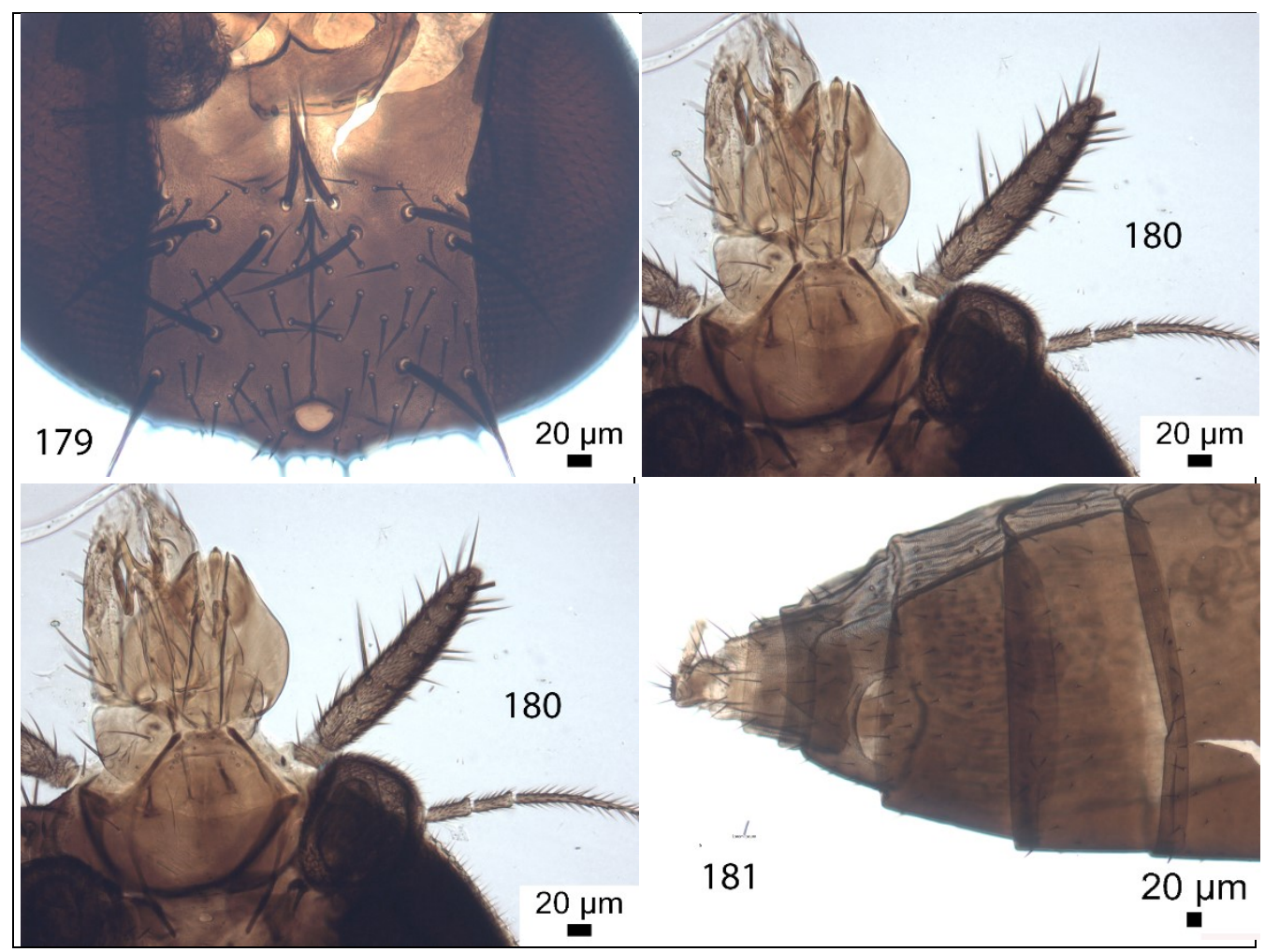

Figs 179-185. Woodiphora, species E, female; 179 - frons; 180 - antennae and palps; 181 - abdomen. 


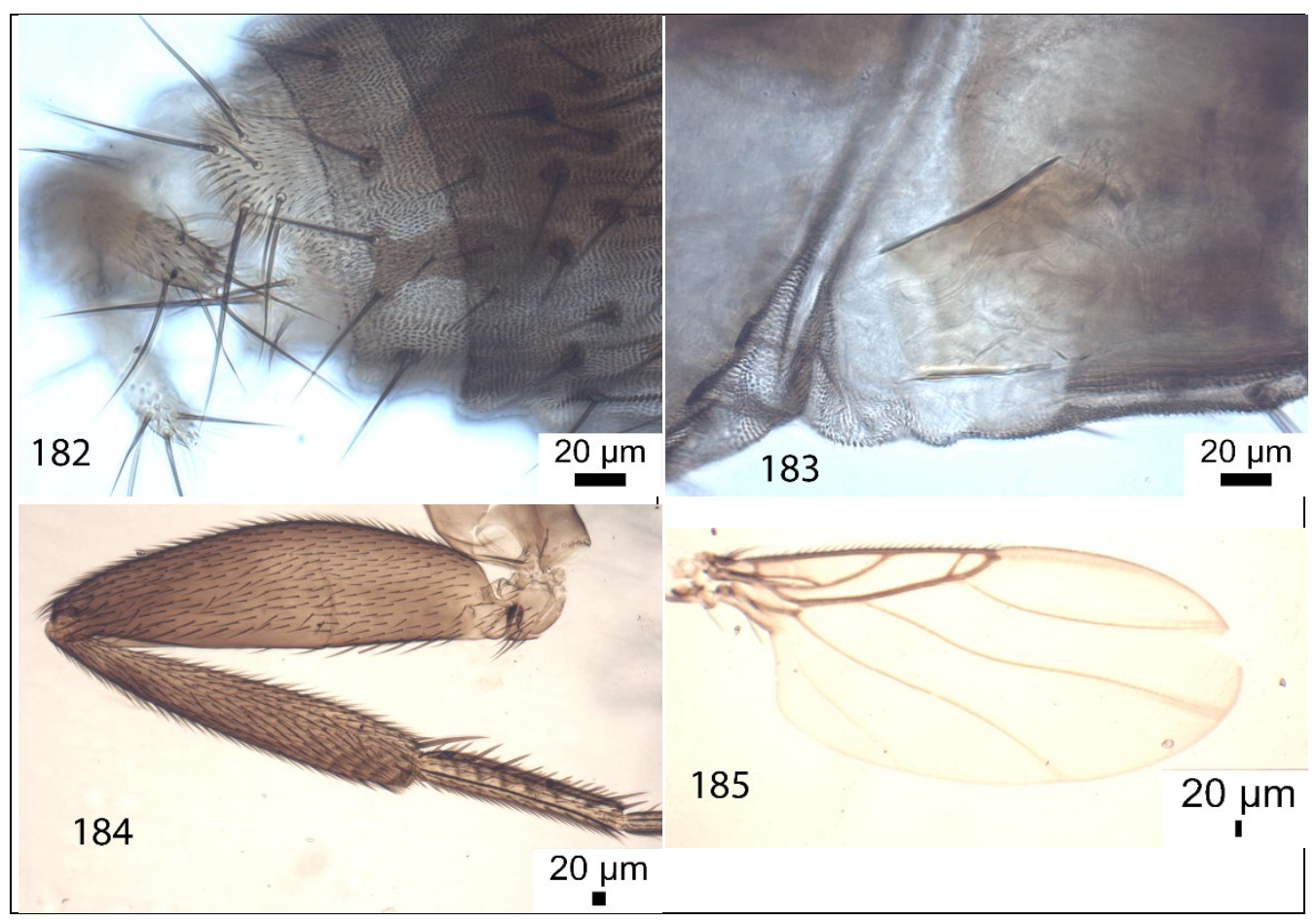

Figs 182-185. Woodiphora, species E, female; 182 - sternite 7 and sternum 8; 183 - furca; 184. - hind femur; 185 - wing.

\section{ACKNOWLEDGEMENTS}

I am grateful to Nigel Wyatt (Natural History Museum, London) for the loan of type specimens. My work on Phoridae is currently funded by the Balfour-Browne Trust (University of Cambridge).

\section{REFERENCES}

BÄNZIGER H. \& DiSNEY R. H. L. 2006. Scuttle flies (Diptera: Phoridae) imprisoned by Aristolochia baenzigeri (Aristolochiaceae) in Thailand. Mitteilungen der Schweizerischen Entomologischen Gesellschaft 79: 29-61.

BorgmeIER T. 1967a. Studies on Indo-Australian Phorid flies, based mainly on material of the Museum of Comparative Zoology and the United States National Museum (Diptera, Phoridae). Studia Entomologica, Petropolis 9: 129-328 (1966).

BORGMEIER T. 1967b. Studies on Indo-Australian phorid flies, based mainly on material of the Museum of Comparative Zoology and the United States National Museum. Part II. Studia Entomologica, Petropolis 10: 81-276.

BRUES C. T. 1911. The Phoridae of Formosa collected by Mr. H. Sauter. Annales Historico-Naturales Musei Nationalis Hungarici 9: 530-559.

DisNeY R. H. L. 1989. A key to Australasian and Oriental Woodiphora (Diptera: Phoridae), affinities of the genus and descriptions of new species. Journal of Natural History 23: 1137-1175.

DiSNEY R. H. L. 1990b. Key to Dohrniphora males (Diptera: Phoridae) of the Australasian and Oriental Regions with descriptions of new species. Zoological Journal of the Linnean Society 99: 339-387.

Disney R. H. L. 1990c. A revised key to Australasian and Oriental Conicera (Diptera: Phoridae), with three new species. Entomologica scandinavica 21:339-344.

Disney R. H. L. 1997. The Micronesian Megaselia curtissima Beyer (Dipt., Phoridae) is a species of Woodiphora. Entomologist's Monthly Magazine 133: 115-116.

DiSNEY R. H. L. 1999a. A troublesome sibling species complex of scuttle flies Diptera: Phoridae) revisited. Journal of Natural History 33: 1159-1216. 
DiSNEY R. H. L. 1999b. New species and a new key to Oriental Puliciphora (Diptera: Phoridae). Entomologica scandinavica 30: 243-248.

DisNeY R. H. L. 2001a. The preservation of small Diptera. Entomologist's Monthly Magazine 137: 155-159.

DiSNEY R. H. L. 2005a. The 'distinctive' Woodiphora parvula Schmitz (Dipt., Phoridae) is a sibling species complex. Entomologist's Monthly Magazine. 141: 143-150.

Disney R. H. L. 2005b. Two new species of Dohrniphora Dahl (Dipt., Phoridae) from the Far East. Entomologist's Monthly Magazine. 141: 197-200.

DiSNEY R. H. L. 2006. Two new sibling species of Megaselia consueta (Collin) (Dipt., Phoridae) from Arabia and the Seychelles. Entomologist's Monthly Magazine 142: 115-125.

DiSNEY R. H. L. 2009. Superfamily Platypezoidea Family Phoridae. In: GERLACH J. (ed.) Seychelles Fauna Monographs. The Diptera of the Seychelles islands. Chapter 11: 167-236. Pensoft Series Faunistica 85. Sofia-Moscow, 431 pp. ISBN 978-954-642-461-7

DisNeY R. H. L. 2016. A remarkable new species of Megaselia Rondani and the hitherto undescribed female of Triphleba truncata Michailovskaya (Diptera: Phoridae) from Russia. Entomologist's Monthly Magazine 152: 173-179.

DisNeY R. H. L. \& BÄNZIGER H. 2009. Further records of scuttle flies (Diptera: Phoridae) imprisoned by Aristolochia baenzigeri (Aristolochiaceae) in Thailand. Mitteilungen der Schweizerischen Entomologischen Gesellschaft 82: 233-251.

DisneY R. H. L., Li G-X. \& Li D. 1997. A new species of Megaselia Rondani (Diptera, Phoridae) and two new records from mainland China. Giornale Italiano di Entomologia 7: 333-338 (1995).

Disney R. H. L., Lizon À L'Allemand S., von BeEREN C. \& WitTe V. 2009. A new genus and new species of scuttle flies (Diptera: Phoridae) from colonies of ants (Hymenoptera: Formicidae) in Malaysia. Sociobiology 53: 1-12.

FANG H., HAI B. \& LIU G-C. 2009. A new species and two new records of Megaselia Rondani (Diptera, Phoridae) from China. Entomotaxonomia 31: 135-139.

FANG H. \& LiU G-C. 2005a. A new species of Megaselia Rondani (Diptera, Phoridae) from Guangdon, China. Acta Zootaxonomica Sinica 30: 636-638.

FANG H. \& LiU G-C. 2005b. A new species of genus Megaselia Rondani (Diptera, Phoridae) from Hainan, China. Entomotaxonomia 27: 289-291.

FANG H. \& LIU G-C. 2012. Two new species of Megaselia Rondani (Diptera: Phoridae) from China. Entomotaxonomia 34: $320-324$.

FANG H. \& LIU G-C. 2015. Three new species of Megaselia Rondani (Diptera, Phoridae) from mailand (sic) China. Zootaxa 3999 (1): 135-143. DOI: 10.11646/zootaxa.3999.1.9

FANG H. XIA, F. \& LiU G-C. 2009. Two new species and one new record of Megaselia Rondani from China (Diptera, Phoridae). Acta Zootaxonomica Sinica 34: 261-264.

LIU G-C. 2000. Taxonomic study on Conicera Meigen (Diptera: Phoridae). In: ZHANG Y. (ed.). Proceedings of 5th National Conference of Insect Taxonomy. China: China Agriculture Press, Chapter 32: 162-173. Chinese Phorid Flies Diptera: Phoridae (part 1). China: Neupress. 292 pp.

LIU G., 2001. A Taxonomic Study of Chinese Phorid Flies Diptera: Phoridae (Part 1). China: Neupress. 292 pp.

LIU G-C. 2015. Revision of the genus Dohrniphora Dahl (Diptera: Phoridae) from China. Zootaxa 3986 (3): $307-331$.

Maruyama M. \& Disney R. H. L. 2008. Scuttle flies associated with Old World army ants in Malaysia (Diptera: Phoridae; Hymenoptera, Formicidae, Dorylinae). Sociobiology 51, 65-71.

MeIJERE J. C. H. DE. 1912. Ueber die Metamorphose von Puliciphora und ueber neue Arten der Gattungen Puliciphora Dahl und Chonocephalus Wandolleck. Zologische Jahrbücher (Supplement) 15: 141-154.

SCHMITZ H. 1927. Revision der Phoridgattungen, mit Beschreibung neuer Gattungen und Arten. Natuurhistorisch Maandblad 16: 30-40, 45-50, 59-68, 72-79, 92-100, 110-116, 128-132, 142-148, 164, 176.

SCHMitz H. \& BeYER E., 1965, Phoridae. In: LindNER E (ed.), Die Fliegen der palaearktischen Region 4 (33) (Lieferung 258, 260): 513-608. Stuttgart, E. Schweizerbart'sche Verlagsbuchhandlung.

YANG C-K. \& WANG X. 1993. Two new species of the genus Puliciphora (Diptera: Phoridae) from Guizhou. Entomotaxonomia 15: 323-226.

ZHANG, R-L. \& LiU G-C. 2009. A new species and a new record species of genus Conicera (Diptera, Phoridae) from China. Acta Zootaxonomica Sinica 34: 472-474.

Zuha R. J. \& Disney,R. H. L. 2017. Records of Woodiphora Schmitz (Diptera: Phoridae) from animal carcasses in Bangi, Malaysia. Serangga: 22 (1): 161-177.

ZhU, W \& LIU G-C. 2009. Two new species of Woodiphora Schmitz (Diptera, Phoridae) from China. Acta Zootaxonomica Sinica 34: 457-459. 


\section{STRESZCZENIE}

[Zadrowate (Diptera, Phoridae) odwiedzające kwiaty Cryptogorynae crispatula (Araceae), w tym opisy nowych gatunków Phoridae (Yunnan, Chiny)]

W pracy zostało opisanych siedem gatunków zadrowatych z Chin, nowych dla nauki: Dohrniphora guangchuni n. sp., Megaselia duolobata n. sp., M. excrispatula n. sp., $M$. interstinctus n. sp., M. leptotibiarum n. sp., M. menglaensis n. sp., M. shooklinglowae n. sp.

Ponadto, przedstawiono opisy 13 gatunków Phoridae, które można będzie nazwać dopiero po powiązaniu z opisem płci przeciwnej (samice i samce). Dotyczy to jednego gatunku z rodzaju Conicera, jednego z rodzaju Megaselia, sześciu z rodzaju Puliciphora i pięciu z rodzaju Woodiphora 